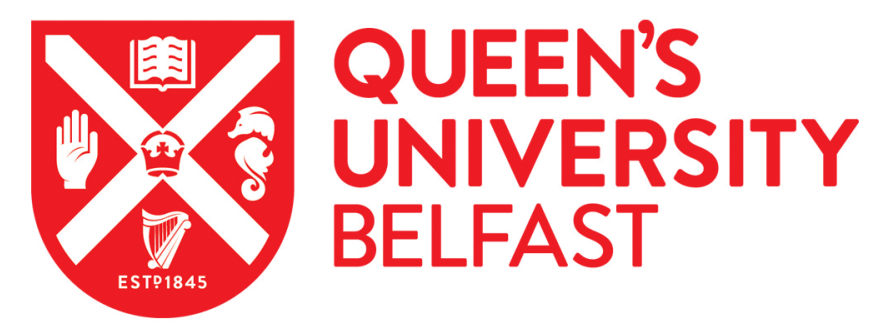

\title{
Thermal investigation and kinetic modeling of lignocellulosic biomass combustion for energy production and other applications
}

Osman , A. I., Abdelkader, A., Johnston, C. R., Morgan, K., \& Rooney, D. W. (2017). Thermal investigation and kinetic modeling of lignocellulosic biomass combustion for energy production and other applications. Industrial and Engineering Chemistry Research, 56, 12119-12130. https://doi.org/10.1021/acs.iecr.7b03478

Published in:

Industrial and Engineering Chemistry Research

Document Version:

Peer reviewed version

Queen's University Belfast - Research Portal:

Link to publication record in Queen's University Belfast Research Portal

Publisher rights

Copyright 2017 American Chemical Society. This work is made available online in accordance with the publisher's policies. Please refer to any applicable terms of use of the publisher.

\section{General rights}

Copyright for the publications made accessible via the Queen's University Belfast Research Portal is retained by the author(s) and / or other copyright owners and it is a condition of accessing these publications that users recognise and abide by the legal requirements associated with these rights.

Take down policy

The Research Portal is Queen's institutional repository that provides access to Queen's research output. Every effort has been made to ensure that content in the Research Portal does not infringe any person's rights, or applicable UK laws. If you discover content in the Research Portal that you believe breaches copyright or violates any law, please contact openaccess@qub.ac.uk. 


\title{
Thermal investigation and kinetic modeling of lignocellulosic biomass
} combustion for energy production and other applications

\author{
Ahmed I. Osman ${ }^{\mathrm{a}, \mathrm{b}^{*}}$, Adel Abdelkader ${ }^{\mathrm{b}}$, Christopher R. Johnston ${ }^{\mathrm{c}}$, \\ Kevin Morgan ${ }^{a}$, David W. Rooney ${ }^{a}$

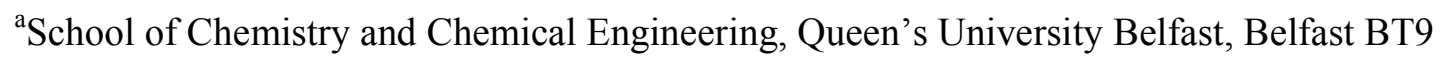 \\ 5AG, Northern Ireland, UK \\ ${ }^{\mathrm{b}}$ Chemistry Department, Faculty of Science - Qena, South Valley University, Qena 83523 - \\ Egypt. \\ ${ }^{\mathrm{c}}$ Agri-Food and Biosciences Institute (AFBI), Hillsborough BT26 6DR, Northern Ireland, UK. \\ Corresponding Author: Ahmed Osman \\ Email: aosmanahmed01@qub.ac.uk \\ Address: School of Chemistry and Chemical Engineering, Queen's University Belfast, David \\ Keir Building, Stranmillis Road, Belfast BT9 5AG, Northern Ireland, United Kingdom
}

Fax: +442890974687

Tel.: +442890974412 


\begin{abstract}
Herein, we studied the combustion and pyrolysis for miscanthus $\times$ giganteus (Elephant Grass) using TG/DSC techniques. Currently, miscanthus is used to an extent in energy generation applications however; issues with regards to its physicochemical combustion characteristics currently hinder this uptake. In this work, the thermal and kinetic analysis of dry miscanthus and its char were investigated for a better understanding of its physicochemical combustion characteristics and consequently, achieving the highest benefit from the combustion process. Different kinetic modeling has been used to calculate the activation energy and the kinetic parameters during combustion/pyrolysis such as the ASTM-E698, Flynn-Wall and Ozawa (FWO) and differential iso-conversional methods. It was observed that the activation energy values were $22.3,40-150$ and $40-165 \mathrm{~kJ} \mathrm{~mol}^{-1}$ for miscanthus, respectively. Furthermore, miscanthus species were tested in wastewater treatment and showed a potential for the rapid removal of cadmium heavy metal. In addition, a study of miscanthus ash was performed and indicated that it can be used as a source of potassium in the fertiliser industry.
\end{abstract}

Keywords: Miscanthus, combustion, energy carrier, thermal, kinetic analysis, Pyrolysis. 


\section{Introduction}

The global demand for energy is growing and it is expected to increase by about $50 \%$ during the next two decades and is projected to reach around 778 EJ by 2035 which represents a great challenge for all countries ${ }^{1}$. Fossil fuels, including coal, natural gas, crude oil and its derivatives, still represents the primary energy source worldwide. Fossil fuel reserves are, however, limited and will soon come to an end ${ }^{2-4}$ while burning them will continue to cause serious environmental and health concerns ${ }^{5-7}$. An important candidate for meeting the future energy sustainably is biomass which can be converted into liquid biofuel or a solid energy carrier $^{2,8-11}$. In 2007, the European Union set a target of increasing its share from renewable energy sources to $20 \%$ of the EU total energy consumption by 2020 , which is a part of the 20 20-20 target with the combined reduction of EU greenhouse gas emissions to $20 \%$ and improvement in the EU's energy efficiency by $20 \%$ on 1990 levels ${ }^{12}$. In Europe, biomass is the main feedstock for renewable energy production as required by the EU commission ${ }^{13}$.

Five basic categories of biomass materials are used for the production of biofuel and solid energy carrier including energy crops, virgin wood, agricultural residues, food wastes, and industrial wastes and co-products ${ }^{2,14}$. The energy crop category is considered to be the most important biomass group for bioenergy production. These are non-food crops rich in lignocellulose which make it a good raw material for the production of heat \& electricity, biofuels or biomaterials ${ }^{15-21}$. Among all the non-food energy crops, miscanthus is considered to be a suitable bioenergy source as a result of its ability to grow in more marginal soils and climate conditions, while also requiring relatively low maintenance and provides a high yield/energy content ratio ${ }^{15,22}$. Miscanthus is a perennial rhizomatous lignocellulosic crop with the $\mathrm{C}_{4}$ photosynthetic pathway ${ }^{23}$. Since the $1980 \mathrm{~s}$, miscanthus has been considered as a promising energy crop in Europe with its current use being mainly for the production of heat and electricity ${ }^{23-25}$. Miscanthus $x$. giganteus, the most popular species, is currently farmed in 
Europe for electricity and heat generation in combined heat and power (CHP) plants and to a smaller degree as a feedstock for biofuels production.

The energy stored in miscanthus, as biomass, can be extracted in various ways, however, most require a pre-treatment step ${ }^{26,27}$. Two main technologies used for the conversion of lignocellulosic biomass are thermochemical and biochemical technologies ${ }^{28}$. Biochemical conversion can occur by either digestion or fermentation ${ }^{26}$ while thermochemical conversion can occur by four different technologies ${ }^{26}$ :

(i) Combustion, which is the burning of biomass in air within a temperature range of $800-1000^{\circ} \mathrm{C}$ to produce hot gases and ash and consequently converting the stored chemical energy into heat, kinetic and thus electrical energy.

(ii) Gasification, in which the biomass is exposed to partial oxidation at high temperatures $\left(800-1500^{\circ} \mathrm{C}\right)$ to convert it into a combustible gas mixture. The low energy gas produced can be burnt directly or used as a fuel for gas engines and gas turbines, while the medium energy gas can be used for the production of chemicals.

(iii) Pyrolysis, which is the conversion of biomass to solid, liquid and gaseous fractions. Pyrolysis is the first physical-chemical step that take place in all thermochemical reactors during combustion or gasification.

(iv) Liquefaction, which is the conversion of biomass into stable liquid hydrocarbons in low temperatures $\left(200-400^{\circ} \mathrm{C}\right)$ and high hydrogen pressures $\left((2-20) 10^{6} \mathrm{~Pa}\right)$.

The direct combustion of miscanthus for electricity and heat generation represents the simplest and the main route for the valorization and its conversion to useful energy $22,23,29,30$. Currently, miscanthus is used to an extent in energy generation applications however, issues with regards to physicochemical combustion characteristics currently hinder this uptake. Therefore, studying the combustion behaviour of miscanthus is crucial to further understand its physicochemical combustion characteristics and consequently, achieve the greatest benefit 
from the combustion process as a conversion method. For this purpose, a study of the thermal behaviour and kinetic parameters during miscanthus combustion was carried out using TG (Thermal Gravimetric) and DSC (Differential Scanning Calorimetry) techniques. The modelfitting and the iso-conversional methods can be applied to a series of DSC/TGA experiments at different heating rates to detect the kinetic data during the thermal combustion of miscanthus. The latter method is considered to be more accurate than the former one which tends to produce highly unreliable values of kinetic parameters ${ }^{31}$. Studying the thermal kinetics using the iso-conversional method allows the estimation of the activation energy as a function of conversion with no need for information about reaction mechanism model ${ }^{31}$. In addition, it can describe the kinetics of multi-step processes during the combustion via a variation of the activation energy with the extent of conversion ${ }^{31}$.

In the second part of our study, we propose a novel approach of new applications of miscanthus species. In addition to using Miscanthus $x$. giganteus as an energy source, its biochar, produced by heating in the absence of air $\approx 500^{\circ} \mathrm{C}$ (Pyrolysis), can be used as an effective soil improver. It has been found that miscanthus biochar is rich in phytoliths $\left(\mathrm{SiO}_{2} \cdot \mathrm{nH}_{2} \mathrm{O}\right)$, a potentially bio-available silicon source, and as such Miscanthus $x$. giganteus is a high $\mathrm{Si}$ accumulator plant ${ }^{32}$. It is well known that the common composition of fertilizers is N-K-P (nitrogen, phosphorus and potassium). Finding a potassium source for the fertilizer industry is challenging. Potash can offer this $\mathrm{K}$ source, however, it is prone to humidity and has problems for typical agricultural fertilizer ${ }^{33}$. We investigated the composition of miscanthus ash that remains after the combustion process to see if it can offer the $\mathrm{K}$ source for fertilizer composition. There is also a possibility of using dry miscanthus plant or its derivative biochar in heavy metal removal. In the literature, miscanthus biochar has been utilised in Cd removal from aqueous solutions and was reported that the pyrolytic temperature had a substantial effect on the surface structure and elemental properties of miscanthus sacchariflorus biochar and that 
increasing the pyrolytic temperature increased the $\mathrm{Cd}$ removal ${ }^{34}$. It is clear that certain properties of biochar including large specific surface area, porous structure and mineral components make it a potentially effective adsorbent for the removal of pollutants from aqueous solutions ${ }^{35,36}$. To the extent of the authors' knowledge, no research has been carried out on the potential use of such dry, unprocessed plant material for heavy metal removal.

A detailed comprehensive review was published by the ICTAC Kinetics Committee addressing the problems and reporting the essential principals that should be followed to obtain thermal analysis data that are adequate to the kinetic computations ${ }^{37}$.

Herein, the combustion of dry miscanthus plant (DMP) and its biochar is studied using TGA/DSC techniques and the iso-conversional method was used for the calculation of the kinetic parameters from DSC curves. Moreover, new potential applications for these miscanthus species for heavy metal removal and in the composition of fertilizer are proposed. To the best of the authors' knowledge, this is the first detailed kinetic study along with the promising industrial applications of miscanthus species.

\section{Materials and methods}

\subsection{Miscanthus Material Preparation}

The miscanthus was harvested from a 10-yr-old energy crop grown at the Agri-Food and Biosciences Institute (AFBI), Environment \& Renewable Energy Centre, Hillsborough, Northern Ireland (54.453077, -6.086162). The site was formerly long-term grass pasture on Surface Water Gley (Class 1) soil type (Avery,1980) overlying shale till. The plantation has been harvested in February each year after winter senescence using a fine-chop Kemper head harvester, the chopped raw fuel blown into a tractor-drawn silage trailer, drawn off and tipped into a forced air drying bay. Sampling was carried out using British Standards methods; solid biofuels sampling BS EN14778; $2011^{38}$ and particle size distribution BS EN 15149-1; $2010^{39}$. 
Grab samples were collected randomly from each load and combined to form a bulk sample for moisture content, performed according to the oven drying method- (BS EN 14774-3: 2009) ${ }^{40}$ with samples sub-divided, placed into a drying oven (Gallenkamp) for 48 hrs at $80^{\circ} \mathrm{C}$ and dried until a constant final weight. The miscanthus fuel used herein had the same chain of custody after their receipt in a dry and crushed form, taking into consideration that the information related to the conditions of miscanthus growth, prior-harvest, post-harvest and handling/storage is irrelevant in our study (Figure S1). The compositional, proximal and ultimate analysis of the miscanthus fuel were performed and reported in Table $\mathrm{S} 1^{41}$.

\subsection{Cadmium heavy metal solution preparation:}

The cadmium heavy metal solution was prepared by dissolving an appropriate amount of $\mathrm{Cd}\left(\mathrm{NO}_{3}\right)_{2} \cdot 4 \mathrm{H}_{2} \mathrm{O}$ in deionised water to get the final desired Cd concentration of $100 \mathrm{mg} \mathrm{L}^{-1}$. The appropriate amount of miscanthus dry plant (DMP) or its biochar was subsequently placed in a bottle containing the $\mathrm{Cd}$ heavy metal solution. Water samples were taken after an hour then at different time intervals i.e. 1, 3 and 7 days to be analysed by the Inductively coupled plasma optical emission spectrometry (ICP-OES) that was used to determine the $\mathrm{Cd}$ metal concentration in the absorption tests. The Cd solution was analyzed with an ICP Optical Emission Spectrometer (Optima 4300 DV, Perkin-Elmer).

\subsection{Miscanthus Characterization}

Brunauer-Emmett-Teller (BET) analysis was performed using a Micromeritics ASAP 2020 system. BET surface area and pore volume were measured by $\mathrm{N}_{2}$ adsorption and desorption isotherms at liquid nitrogen temperature $\left(-196^{\circ} \mathrm{C}\right)$.

Compositions of the DMP were characterized by means of proximate and ultimate analyses. Elemental (C, H and N) Analysis was performed using a Perkin Elmer PE2400 CHNS/O Elemental Analyzer. The oxygen content was calculated by difference from the data obtained 
by a Perkin Elmer PE2400 CHNS/O Elemental Analyzer. Proximate analysis was carried out according to the ASTM method to determine the \% of moisture (ASTM D2867-95), volatile matter (ASTM D5832-95), ash content (ASTM D2866-94), char and fixed carbon (by difference) ${ }^{42,43}$. Char and volatile contents were determined using Thermogravimetry (TGA), with heating to $900{ }^{\circ} \mathrm{C}$ at a rate of $10{ }^{\circ} \mathrm{C} \mathrm{min}^{-1}$ and holding the temperature for 10 min to ensure constant final weight, ${ }^{44}$. Again with the TGA, \% Ash was obtained by heating to 500 ${ }^{\circ} \mathrm{C}$ with a heating rate of $10{ }^{\circ} \mathrm{C} \min ^{-1}$ then heating to $575{ }^{\circ} \mathrm{C}$ with $2.5{ }^{\circ} \mathrm{C} \mathrm{min}{ }^{-1}$ and holding for $10 \min ^{44}$.

Scanning Electron Microscopy (SEM) was carried out on a FEI Quanta 250 FEG MKII with a high-resolution environmental microscope (ESEM) using XT Microscope Control software and linked to an energy-dispersive X-ray (EDX) detector. Two types of detectors were used in SEM analysis; the Everhart-Thornley Detector (ETD) which is used to detect secondary electrons emitted from the sample and Back-Scattered Electron Detector (BSED) which is used to measure the backscattered electrons from the sample, where the elements of higher atomic number appear brighter in the image due to emitting a large number of back-scattered electrons (BSE). The EDX used was a $10 \mathrm{~mm}^{2}$ silicon drift detector (SDD)-x-act from Oxford Instruments which utilizes Aztec ${ }^{\circledR}$ EDS analysis software. Both systems used the same chamber.

TGA was performed at a specific heat range with different heating rates of 2.5, 10, 20 and 30 ${ }^{\circ} \mathrm{C} \mathrm{min}{ }^{-1}$, in a stream of dry $\mathrm{N}_{2}$ flowing at $40 \mathrm{~cm}^{3} \mathrm{~min}^{-1}$, using a simultaneous thermal analysis Mettler Toledo (TGA/DSC) Thermogravimetric analyzer Pyris TGA/DSC1. Changes in mass of the sample were recorded during the ramping operation. DSC was used to determine the heat liberated in $\mathrm{W} \mathrm{g}^{-1}$. For the kinetic modeling, the weights of the samples were between 4.93 and $4.97 \mathrm{mg}$ to reduce the effect of heat and mass transfer on the data obtained from the DSC instrument. Prior to the DSC experiments, the instrument was calibrated using indium as 
reference standard. The TGA instrument was also calibrated for buoyancy effects to allow quantitative estimation of weight changes. Experiments were performed twice to ensure reproducibility and the standard error was found to be $\pm 1^{\circ} \mathrm{C}$.

\section{Results and Discussion}

\subsection{Miscanthus characterisation}

\subsubsection{FTIR analysis}

The FTIR spectra of the DMP in the wavenumber range of $2500-4000 \mathrm{~cm}^{-1}$ is shown in Figure 1. The inset reports two absorption bands at 2918 and $2849 \mathrm{~cm}^{-1}$ which are attributed to the C-H stretching of cellulose and lignin, respectively ${ }^{45,46}$.

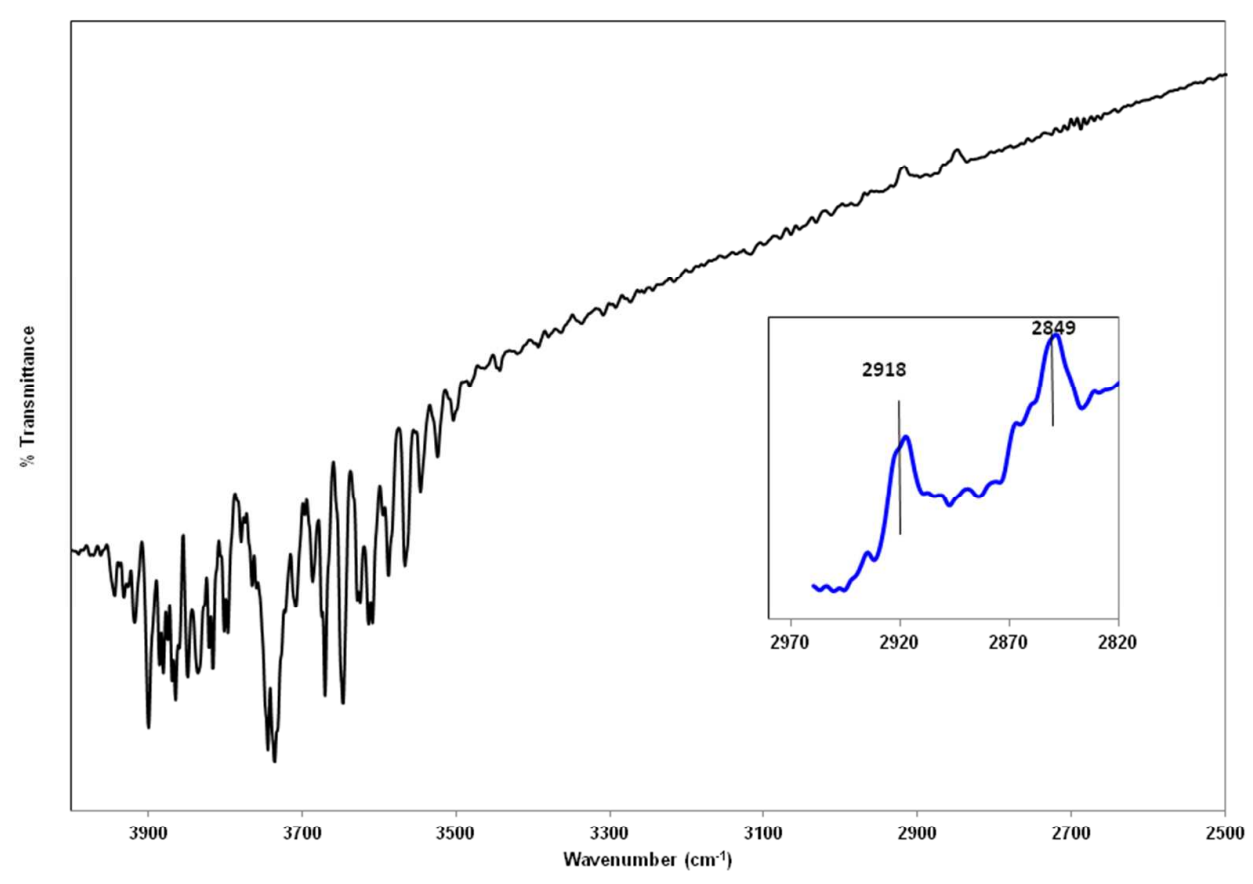

Figure 1: FTIR spectra of dry miscanthus plant (DMP) in the wavenumber range of 2500-4000 $\mathrm{cm}^{-1}$. 


\subsubsection{Thermogravimetric data:}

The percentage composition of the cellulose, hemicellulose and lignin in the lignocellulosic biomass are in the range of $40-60,20-40$ and $10-25 \mathrm{wt} \%$, respectively, and it has been previously reported for miscanthus as 41,30 and $22 \%$, respectively ${ }^{44}$. The complete and partial combustion of hemicellulose produces $\mathrm{CO}_{2}$ and $\mathrm{CO}$ gases, respectively. The emission of these gases are due to the pyrolysis of the carboxylic groups in the unbranched structure of saccharides (xylose, mannose, glucose, galactose, etc) which are easily removed during pyrolysis ${ }^{47}$. There is usually a complete combustion of hemicellulose which emits $\mathrm{CO}_{2}$ and water vapour. In contrast, the pyrolysis of cellulose, which contains $\mathrm{OH}$ and $\mathrm{C}-\mathrm{O}$ groups, emits mainly $\mathrm{CO}$ which comes from the pyrolysis of the unbranched long polymers of glucose and consequently, cellulose decomposes at a higher temperature than hemicellulose, meaning complete combustion is more difficult to achieve. Lignin, however, is the only component which is responsible for emitting $\mathrm{H}_{2}$ and $\mathrm{CH}_{4}$ gases during pyrolysis and this is due to the pyrolysis of the branched aromatic rings and methoxyl groups $\left(-\mathrm{O}-\mathrm{CH}_{3}\right)$ which are, therefore, even more difficult to decompose ${ }^{48}$.

\subsubsection{DSC at high heating rates:}

The DSC curves of DMP at different heating rates (i.e. $2.5,10,20$ and $30{ }^{\circ} \mathrm{C} \min ^{-1}$ ) under air atmosphere is shown in Figure 2. It is not surprising that with increasing the heating rates, a shift toward higher peak decomposition was observed. The ignition and burnout temperatures along with the heat liberated at different heating rates were calculated from the DSC curves and presented in Figure 3 and Table S2. The ignition temperature logically increased with increasing heating rates and this is in agreement with Figure 2 and the work done by Kok and Ozgur ${ }^{49}$. The burnout temperature increased by $75^{\circ} \mathrm{C}$ with increasing the heating rate from 2.5 to $10{ }^{\circ} \mathrm{C} \mathrm{min}^{-1}$. However, a slight increase was observed with increasing the heating rate from 
10 to $30{ }^{\circ} \mathrm{C} \min ^{-1}$. The heat liberated during the DMP combustion increased by $4625 \mathrm{~W} \mathrm{~g}^{-1}$ with increasing the heating rate from 2.5 to $30{ }^{\circ} \mathrm{C} \mathrm{min}^{-1}$.

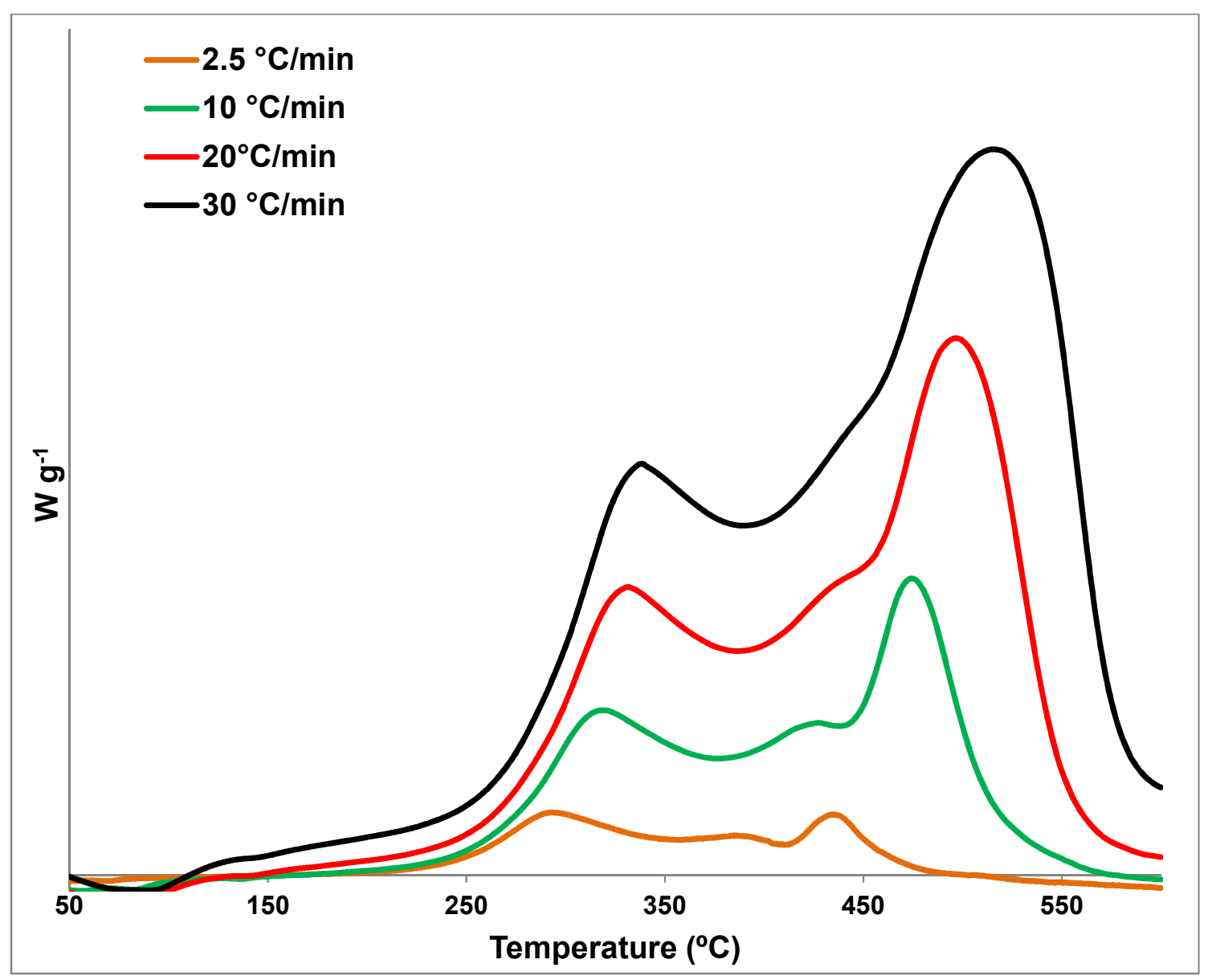

Figure 2: DSC curves of DMP with different heating rates i.e. $2.5,10,20$ and $30{ }^{\circ} \mathrm{C} \mathrm{min}^{-1}$ ) under air atmosphere. 

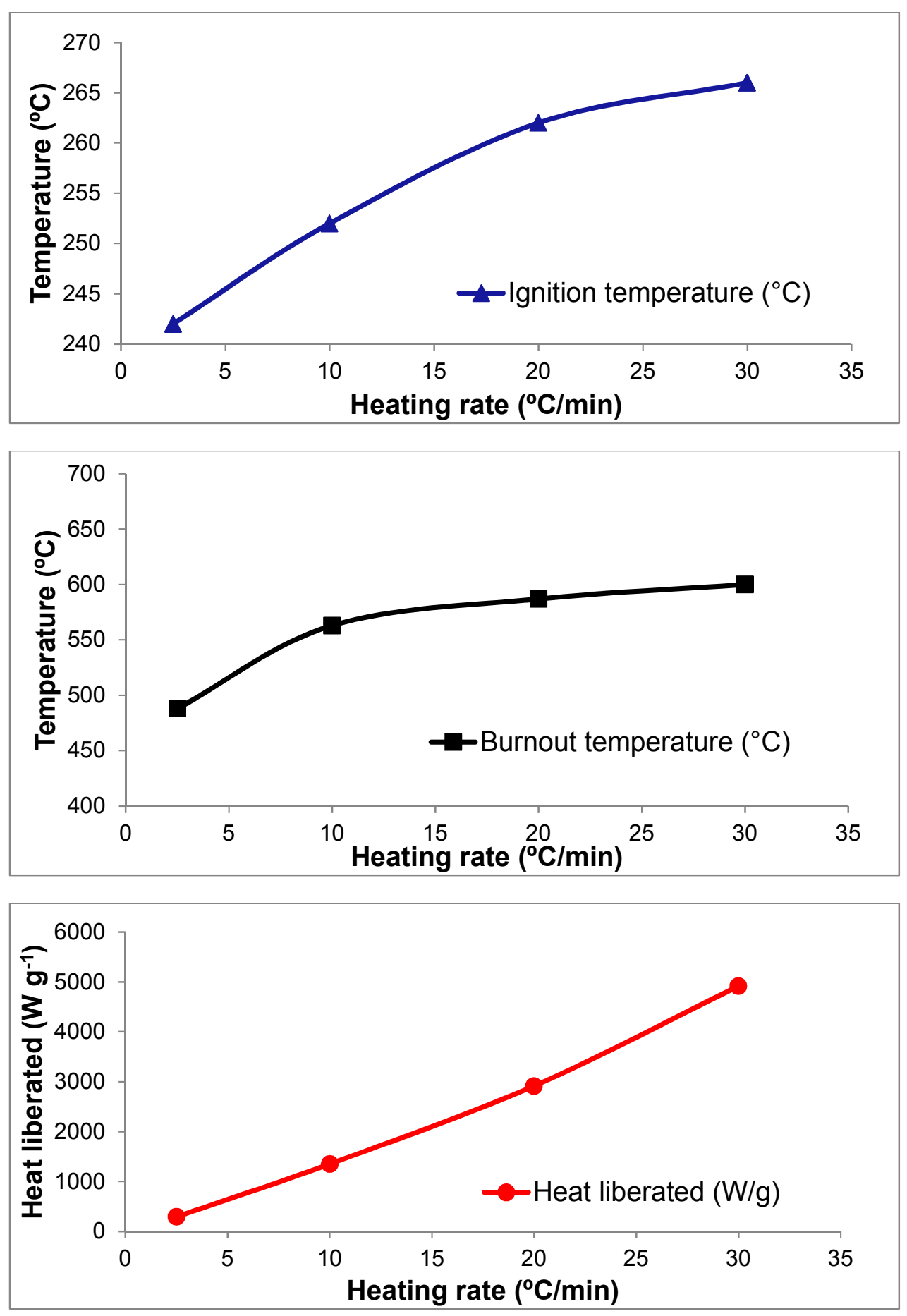

Figure 3: The calculated ignition, burnout temperatures along with heat liberated from the DSC curves of DMP with different heating rates under air atmosphere. 
Figure 4 reports the DSC pyrolysis curves of DMP at different heating rates of 2.5, 10, 20 and $30{ }^{\circ} \mathrm{C} \min ^{-1}$ under $\mathrm{N}_{2}$ atmosphere in order to investigate the pyrolysis of miscanthus. Clearly, the endothermic peak at $80{ }^{\circ} \mathrm{C}$ is ascribed to the dehydration process in the DMP samples. The small endothermic peak appeared at $140{ }^{\circ} \mathrm{C}$ is attributed to the decomposition of the first component (hemicellulose), followed by broad exothermic pyrolysis peak of the mixture of three principal constituents that shifted to higher temperature with increasing heating rate from 2.5 to $30{ }^{\circ} \mathrm{C} \mathrm{min}^{-1}$. The lignin pyrolysis decomposition peaks exhibited at 660,700 and 734 with heating rates of 10,20 and $30{ }^{\circ} \mathrm{C} \mathrm{min}^{-1}$, respectively. These results are in a line with the work reported by Brech et al. ${ }^{50}$ and a distinguishing lignin pyrolysis peak at around $700{ }^{\circ} \mathrm{C}$ was described by Yang et $a l .{ }^{48}$. Alvarez et al. studied the combustion of twenty-eight common biomass types, including miscanthus and they reported that miscanthus showed two temperature ranges of combustion of $240-340$ and $450-550{ }^{\circ} \mathrm{C}$ using the DTG data ${ }^{51}$. Furthermore, they found that the combustion characteristics of the lignocellulosic biomass are about the same, thus they proposed two steps of kinetic reaction as below:

$$
\begin{array}{ll}
X(\text { solid }) \rightarrow Y(\text { solid })+G 1(\text { gas }) & \text { Step } 1 \\
Y(\text { solid }) \rightarrow A(\text { ash })+G 2(\text { gas }) & \text { Step } 2
\end{array}
$$




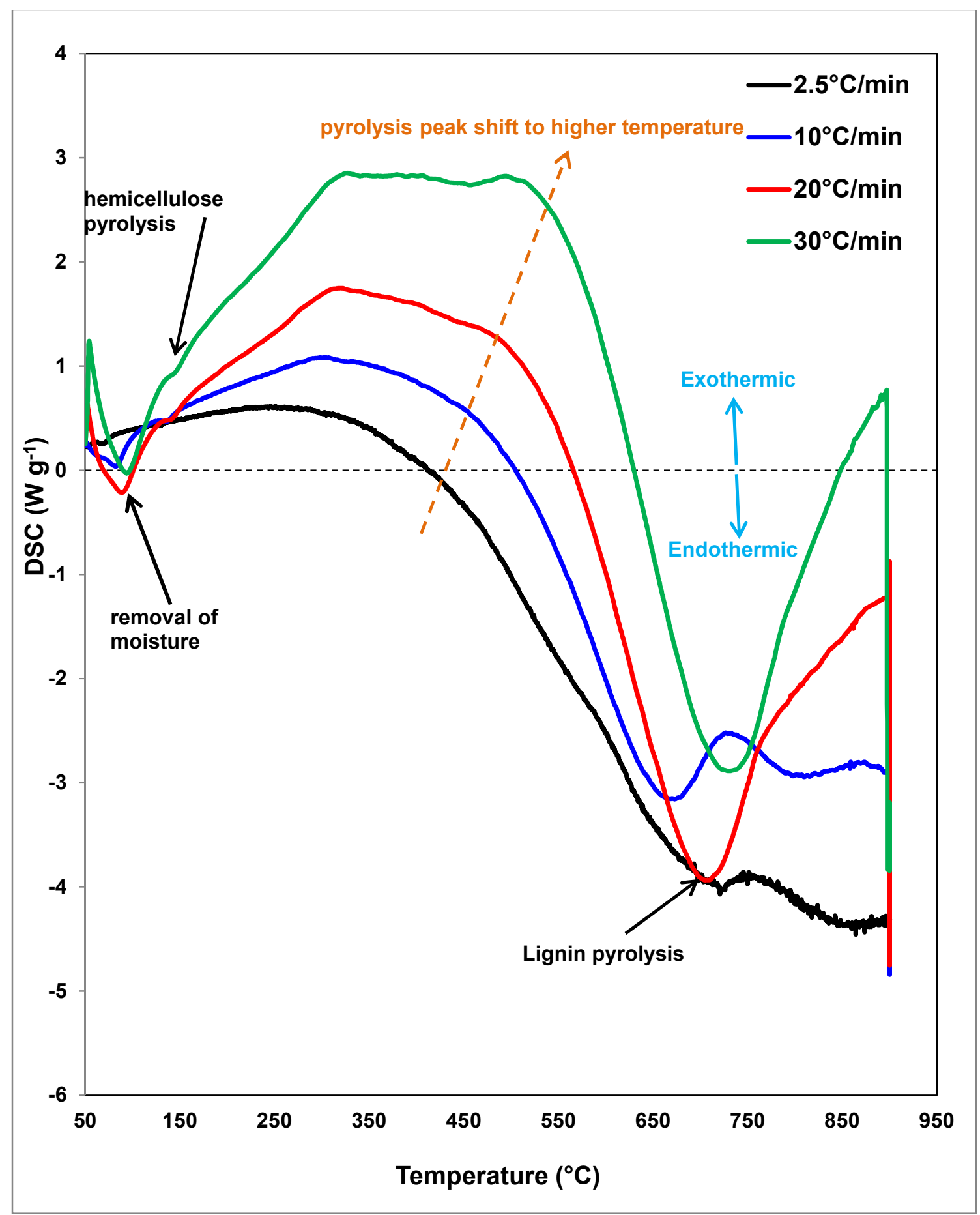

Figure 4: DSC curves of dry DM sample showing the pyrolysis of cellulose, hemicelluloses and lignin under $\mathrm{N}_{2}$ atmosphere $\left(40 \mathrm{ml} \mathrm{min}^{-1}\right)$ at different heating rates of $2.5,10,20$ and $30{ }^{\circ} \mathrm{C}$ $\min ^{-1}$. 
It is well known that the gross calorific value (GCV) or the higher heating value (HHV) of fossil fuel (e.g. coal) is higher than that of lignocellulosic biomass due to the latter having less fixed carbon, more volatile matter and more oxygen and consequently lower GCV ${ }^{52}$. For instance, the average GCV of coal is $20,120 \mathrm{~kJ} \mathrm{~kg}^{-1}$, while it is lower in the case of dry biomass such as wood and baggase with 14,644 and $18,410 \mathrm{~kJ} \mathrm{~kg}^{-1}$, respectively. The GCV of DMP was calculated to be $16,600 \mathrm{~kJ} \mathrm{~kg}^{-1}$, typical among lignocellulosic biomass species used for energy generation. To improve the combustibility of miscanthus, 'Smouldering Combustion' is recommended ${ }^{52,53}$. Typically, upon heating the biomass, it dries, pyrolyzes and, in presence of $\mathrm{O}_{2}$, ignition takes place through flaming (gas phase homogeneous combustion) or smouldering (heterogeneous combustion). Smouldering is the combustion of porous fuels via a slow, flameless and low temperature burning process, considered as the most continual and feasible type of combustion ${ }^{52,53}$. There are many factors affecting the calorific value of the biomass such as its composition, ash content, volatile matter, cultivation technique, fertilizer utilised, soil composition and atmospheric weather conditions. Recently, Huang and Rein ${ }^{53}$ studied the possible mechanisms of smouldering combustion during the thermochemical conversion of biomass in detail. There are three common schemes that can describe the reaction mechanism, the first drying step is the common step between all these mechanisms as shown below ${ }^{53}$ : 
1) Three-steps mechanism

a) Biomass. $\mathrm{H}_{2} \mathrm{O} \rightarrow$ Biomass $+\mathrm{H}_{2} \mathrm{O}$

b) Biomass $\rightarrow \gamma-$ Char + Pyrolysis gas

c) $\gamma-$ Char $+\mathrm{O}_{2} \rightarrow \gamma-\mathrm{ash}+\mathrm{Gas}$

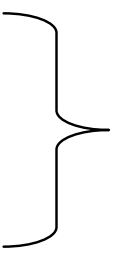

Where $\gamma$-Char is the char produced during the biomass pyrolysis and $\gamma$-ash is the ash produced during the smouldering combustion. This is typically three steps which are (a) drying, (b) pyrolysis and (c) combustion.

2) Five-steps mechanism

a) Biomass. $\mathrm{H}_{2} \mathrm{O} \rightarrow$ Biomass $+\mathrm{H}_{2} \mathrm{O}$

b) Biomass $\rightarrow \gamma-$ Char + Pyrolysis gas

c) Biomass $+\mathrm{O}_{2} \rightarrow \phi-$ Char + Gas

d) $\gamma-$ Char $+\mathrm{O}_{2} \rightarrow \gamma-$ ash + Gas

e) $\phi-C h a r+O_{2} \rightarrow \phi-a s h+$ Gas

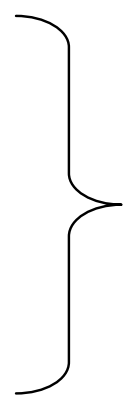

Where $\gamma$-Char and $\boldsymbol{\phi}$-Char are different chars produced during the parallel pyrolysis and oxidation, followed by the oxidation of these chars in the combustion steps $(d, e)$ resulting in the following $\gamma$-ash and $\boldsymbol{\phi}$-ash .

3) Nine-steps mechanism

a) Biomass. $\mathrm{H}_{2} \mathrm{O} \rightarrow$ Biomass $+\mathrm{H}_{2} \mathrm{O}$

b) Hemicellulose $\rightarrow$ hp $\gamma-$ Char $+h p-g a s$

c) Cellulose $\rightarrow$ cpr - Char $+c p-g a s$

d) Lignin $\rightarrow$ lp $\gamma-$ Char + lp - gas

e) Hemicellulose $+\mathrm{O}_{2} \rightarrow$ hoф - Char + Gas

f) Cellulose $+\mathrm{O}_{2} \rightarrow \operatorname{co\phi }-$ Char + Gas

g) Lignin $+\mathrm{O}_{2} \rightarrow$ lo $\phi-$ Char + Gas

h) $(h p, c p, l p) \gamma-$ Char $+O_{2} \rightarrow(h p, c p, l p) \gamma-a s h+$ Gas

i) $(h o, c o, l o) \phi-C h a r+O_{2} \rightarrow(h o, c o, l o) \phi-a s h+G a s$ 
Where, hp $\gamma$-Char, cp $\gamma$-Char and lp $\gamma$-Char are the chars produced during the pyrolysis of hemicellulose, cellulose and lignin, respectively. ho $\phi$-Char, $\operatorname{co} \phi$-Char and lo $\phi$-Char are the oxidised form of hemicellulose, cellulose and lignin, respectively.

In this proposed mechanism, the three different components of biomass (hemicellulose, cellulose and lignin) behave differently and separately i.e. each component pyrolyses producing the equivalent char (steps b, c, d). At the same time, these components oxidise to produce different char compositions (steps e, f, g). Finally, these different chars are oxidised in the combustion steps $(\mathrm{h}, \mathrm{i})$.

\subsection{Kinetic modeling:}

The activation energy and the kinetic parameters were calculated from the DSC curves with different heating $\left(1,2,4\right.$ and $\left.8{ }^{\circ} \mathrm{C} \min ^{-1}\right)$ under air atmosphere as shown in Figure 5. The heating rate of $4{ }^{\circ} \mathrm{C} \min ^{-1}$ was repeated to ensure the reproducibility of the DSC data.

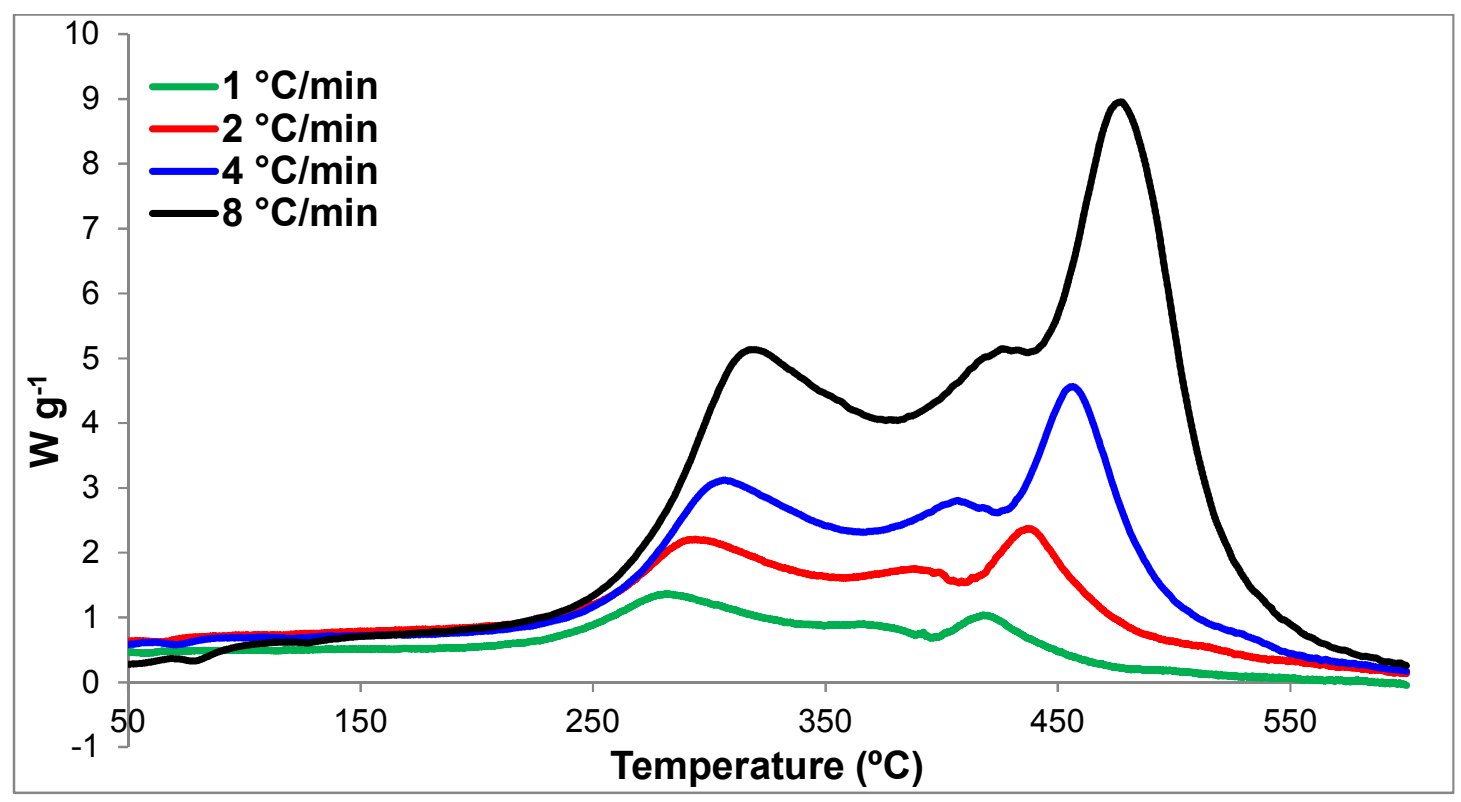

Figure 5: DSC curves of the DMP with different heating rates (i.e. 1, 2, 4 and $8{ }^{\circ} \mathrm{C} \mathrm{min}^{-1}$ ) under air atmosphere. 
The thermal combustion of miscanthus in a CHP boiler is relatively considered as adiabatic process $i$. e. the heat released can get to an exponential increase of temperature along with combustion gases. Thus understanding the thermal kinetic behaviour of miscanthus is crucial in order to identify the physicochemical combustion characteristic that hinders some of the energy generation applications. AKTS software was used in order to determine the activation energy (Ea) and the pre-exponential factor in this study using the iso-conversional methods such as ASTM-E698 and Ozawa-Flynn-Wall and differential iso-conversional method such as the Friedman method.

Model-fitting and model-free (iso-conversional) are the two common methods for studying the DSC/TGA solid-state kinetic data. The model-fitting method is based on the best fitting of the thermogravimetric data with the different models using single DSC/TGA curve. However, this method has drawbacks as the thermogravimetric data might fit with more than one model or given higher kinetic parameter values. On the other hand, the iso-conversional method has advantages over the model fitting method due to its simplicity and the elimination of error related to the model fitting ${ }^{54}$. Different heating rate curves are required to calculate the kinetic parameters in the iso-conversional method as a function of the conversion $(\alpha)$ i.e. Ea calculated for each conversion point. It is well known that the thermal analysis mechanism is complicated as it tends to take place in multiple steps with different reaction rates and as such an isoconversional method is the most suitable method and commonly used in this case. The Kissinger method is the only model-free method that does not detect the Ea as a function of progressive conversion $(\alpha)$ so it is not considered as an iso-conversional method assuming a constant Ea.

The basic principles of model-free (iso-conversional) method are outlined below.

The rate of thermal decomposition of miscanthus can be described in terms of conversion $(\alpha)$ and temperature $(\mathrm{T})$ as in Equation 1: 


$$
\frac{d \alpha}{d t}=k(T) f(\alpha)
$$

Equation 1

Where $\alpha$ can be expressed as the decomposed mass fraction of miscanthus as in Equation 2

$$
\alpha=\frac{m_{i}-m_{a}}{m_{i}-m_{f}} \quad \text { Equation } 2
$$

where: $m_{i}, m_{a}$ and $m_{f}$ are initial, actual and final masses, respectively.

Arrhenius equation describes the temperature dependent function in terms of the activation energy (Ea) and the pre-exponential factor $\left(k_{0}\right)$ as in Equation $3^{55,56}$.

$$
k(T)=k_{0} e^{\left(\frac{-E_{a}}{R T}\right)} \quad \text { Equation } 3
$$

where: Ea is the activation energy in $\mathrm{kJ} \mathrm{mol}^{-1}$, $\mathrm{T}$ is the absolute temperature in Kelvin, $\mathrm{R}$ is the gas constant $\left(8.314 \mathrm{~J} \mathrm{~K}^{-1} \mathrm{~mol}^{-1}\right)$ and $k_{0}$ is the pre-exponential factor $\left(\mathrm{min}^{-1}\right)$.

By combining Equation 1 and 3, the thermal decomposition equation of miscanthus can be expressed as in Equation 4.

$$
\frac{d \alpha}{d t}=k_{0} e^{\left(\frac{-E_{a}}{R T}\right)} f(\alpha) \quad \text { Equation } 4
$$

In the non-isothermal iso-conversional method, using different linear heating rates $\left(\beta=\mathrm{dT}^{\mathrm{dt}}{ }^{-}\right.$

$\left.{ }^{1}\right)$, the thermal decomposition equation can be expressed as in Equation 5

$$
\frac{d \alpha}{d T}=\frac{k_{0}}{\beta} e^{\left(\frac{-E_{a}}{R T}\right)} f(\alpha)
$$

Equation 5

\subsubsection{Non-isothermal iso-conversional methods:}

\subsubsection{ASTM-E698 method:}

This method is suitable for a single step reaction and can be presented as in Equation 6 .

$$
\beta \frac{d \alpha}{d t}=k_{0} e^{\left(\frac{-E_{a}}{R T}\right)}(1-\alpha)
$$

Equation 6

\subsubsection{Flynn-Wall and Ozawa (FWO) method:}

The previous method is not quantitatively appropriate for multiple step reactions such as autocatalytic reactions ${ }^{57}$. The FWO method proposes the calculations of the variations of the 
apparent activation energy in terms of different linear thermogravimetric curves using integral iso-conversional analysis method ${ }^{57,}{ }^{58}$. The Ea can be calculated by plotting the natural logarithm of heating rates $(\ln \beta)$ versus $1000 \mathrm{~T}^{-1}$ which represents a linear relationship with a given $\alpha$ at different heating rates as in Equation 7 .

$$
\ln \beta=\ln \left(\frac{k_{0} \cdot E_{a}}{R \cdot g(\alpha)}\right)-5.331-1.052 \frac{E_{a}}{R . T}
$$

Equation 7

where: $g(\alpha)$ is constant at a given value of $\alpha$.

\subsubsection{Kissinger-Akahira-Sunose method:}

In this method, the Ea can be calculated by plotting the natural logarithm of $\beta \mathrm{T}^{-2}$ versus the temperature inverse ${ }^{44}$ as shown in Equation 8.

$$
\frac{\ln \beta}{T^{2}}=\ln \left[\frac{k_{0} \cdot R}{E_{a} \cdot g(\alpha)}\left(1-\frac{2 R T}{E_{a}}\right)\right]-\left(\frac{E_{a}}{R . T}\right)
$$

Equation 8

\subsubsection{Isothermal iso-conversional methods:}

\subsubsection{Isothermal Friedman method:}

The Friedman method assumes that the thermal decomposition is independent of the temperature but dependent on the reaction progress (rate of the mass loss), hence $f(\alpha)$ is constant at any given $\alpha$. By taking the natural logarithm of both sides of Equation 5, gives Equation 9. Thus by plotting $\ln \beta \frac{d \alpha}{d T}$ versus the inverse temeperature, Ea can be calculated from the slope $\frac{E_{a}}{R}$.

$$
\ln \beta \frac{d \alpha}{d T}=\ln \left[k_{0} f(\alpha)\right]-\frac{E_{a}}{R T}
$$

Equation 9

DSC detects the heat flow of the reaction process during the isothermal experiments ${ }^{59}$, that heat flow during the combustion of DMP under an air atmosphere with different heating rates is shown in Figures 6 and 7 (coloured and black curves are for practical and theoretical data, respectively) along with Table 1 . It is apparent that the decomposition temperature range was 
shifted toward a higher temperature range from $172-487$ to $199-570{ }^{\circ} \mathrm{C}$ by increasing the heating rates from 1 to $8{ }^{\circ} \mathrm{C} \mathrm{min}^{-1}$, respectively. Conversely, the time needed for the thermal decomposition was dramatically decreased with increasing the heating rates. For instance, 7.7 and 1.1 hours is needed for the complete combustion of DMP at heating rates of 1 and $8{ }^{\circ} \mathrm{C}$ $\min ^{-1}$, respectively (Table 1 ). In addition, the peak height increased approximately ten times with increasing the heating rate from 1 to $8{ }^{\circ} \mathrm{C} \min ^{-1}$, while the peak maximum was shifted toward a higher decomposition temperature by $197^{\circ} \mathrm{C}$.

Table 1: Thermal decomposition data of DMP derived from the DSC curves at different heating rates. Sample weight was $\approx 4.9 \mathrm{mg}$ with tangential sigmoid baseline type used during the extraction of DSC data.

\begin{tabular}{|c|c|c|c|c|c|}
\hline $\begin{array}{c}\text { Heating rate } \\
\left({ }^{\circ} \mathrm{C} \text { min }^{-1}\right)\end{array}$ & $\begin{array}{c}\text { Temperature } \\
\text { range }\left({ }^{\circ} \mathrm{C}\right)\end{array}$ & $\begin{array}{c}\text { Time } \\
\text { range(s) }\end{array}$ & $\begin{array}{l}\text { Peak maximum } \\
\left({ }^{\circ} \mathrm{C} \mathrm{s}^{-1}\right)\end{array}$ & $\begin{array}{c}\text { Peak height } \\
\left(\mathrm{W} \mathrm{g} \mathrm{g}^{-1}\right)\end{array}$ & $\begin{array}{l}\text { Heat released } \\
\qquad\left(\mathrm{J} \mathrm{g}^{-1}\right)\end{array}$ \\
\hline 1 & $172-487$ & $8822-27728$ & $281 / 1.5 * 10^{4}$ & 0.794 & 6260 \\
\hline 2 & $180-513$ & $4668-14656$ & $438 / 1.2 * 10^{4}$ & 1.628 & 6481 \\
\hline 4 & $189-546$ & $2464-7822$ & $456 / 6462$ & 3.618 & 6456 \\
\hline 8 & $199-570$ & $1302-4088$ & $478 / 3396$ & 7.319 & 6545 \\
\hline
\end{tabular}



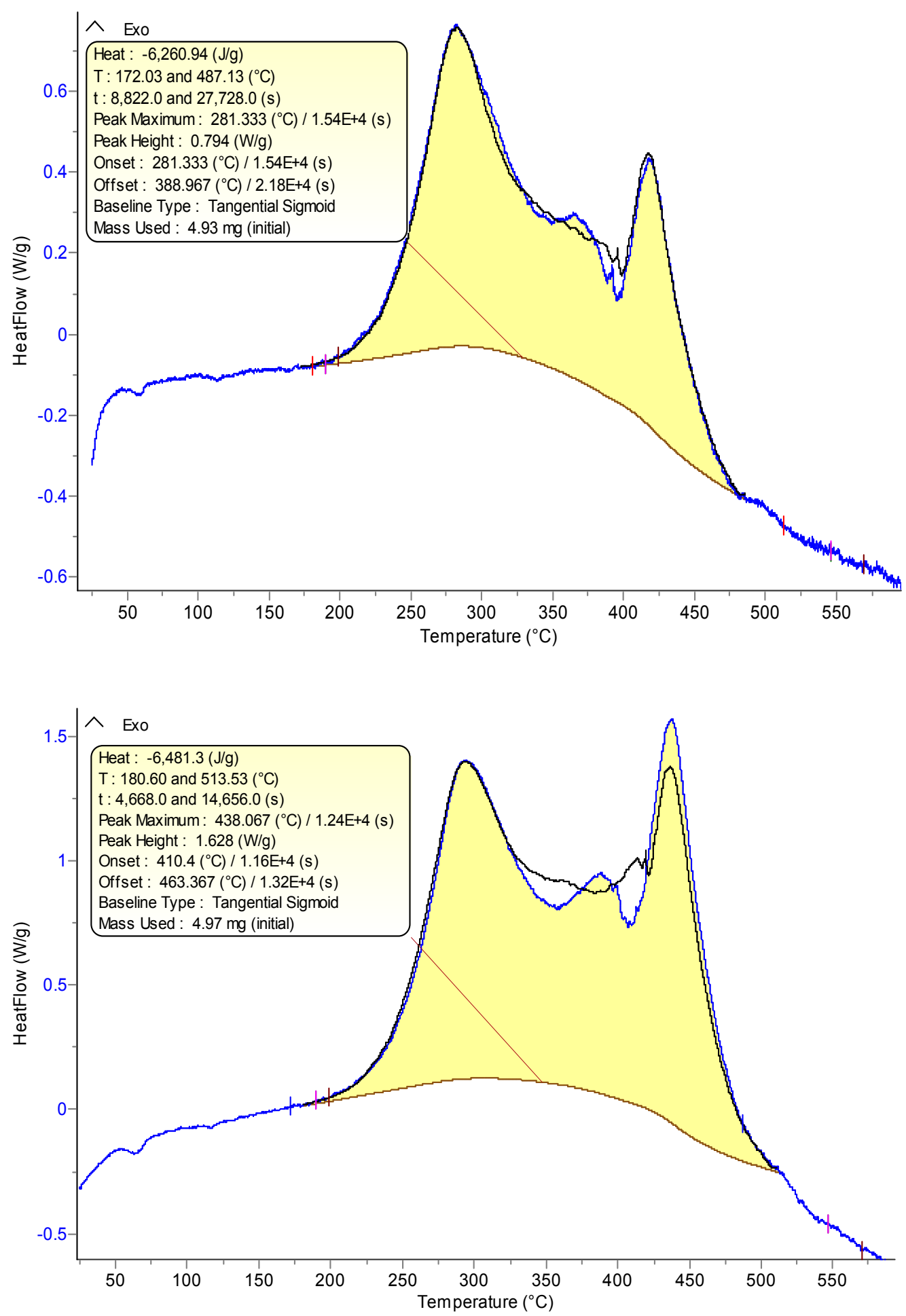

Figure 6: Heat flow of the DMP combustion with heating rates $1{ }^{\circ} \mathrm{C} \min ^{-1}$ (top) and $2{ }^{\circ} \mathrm{C} \min ^{-}$

${ }^{1}$ (bottom) under air atmosphere. The blue and black curves are the experimental and theoretical results, respectively. 

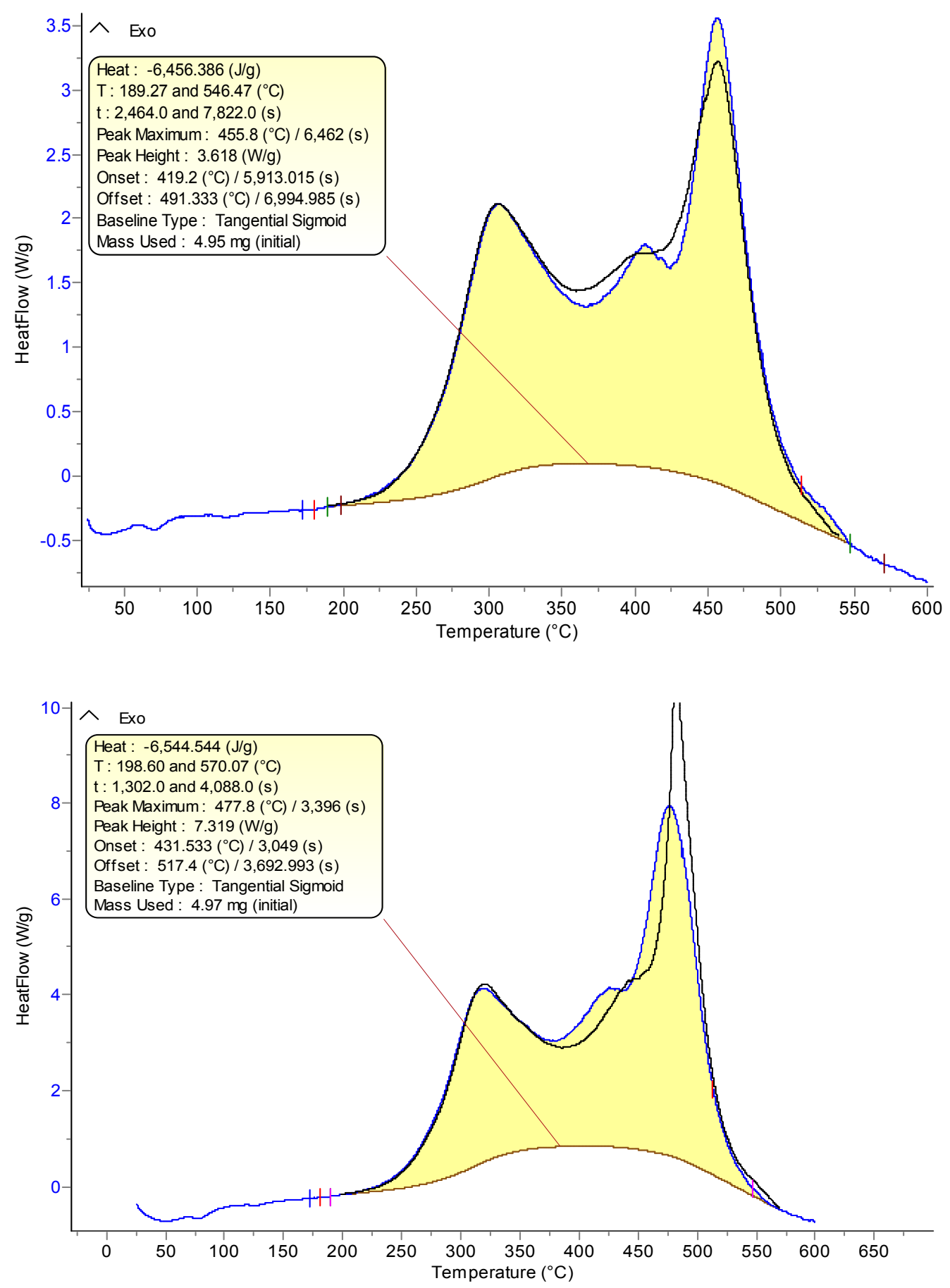

Figure 7: Heat flow of the DMP combustion with heating rates $4{ }^{\circ} \mathrm{C} \min ^{-1}$ (top) and $8{ }^{\circ} \mathrm{C} \min ^{-}$

${ }^{1}$ (bottom) under air atmosphere. The blue and black curves are the experimental and theoretical results, respectively. 
Figure 8 shows the heat released $\left(\mathrm{J} \mathrm{g}^{-1}\right)$ during the reaction progress versus the temperature for the DMP where the coloured and dashed black curves show the practical and theoretical calculations by AKTS software, respectively. Clearly, there is a perfect match between the experimental and the modelled data. The reaction rate $\left(\mathrm{W} \mathrm{g}^{-1}\right)$ versus temperature curves showed a good match only at low heating rates $\left(1,2\right.$ and $\left.4{ }^{\circ} \mathrm{C} \min ^{-1}\right)$ which may be due to the large amounts of heat liberated at a high heating rate $\left(8^{\circ} \mathrm{C} \min ^{-1}\right)$ as seen in Figure 9 . It is difficult for a good match at high heating rates and this finding is in line with the work done by Kumar et al. ${ }^{60}$.

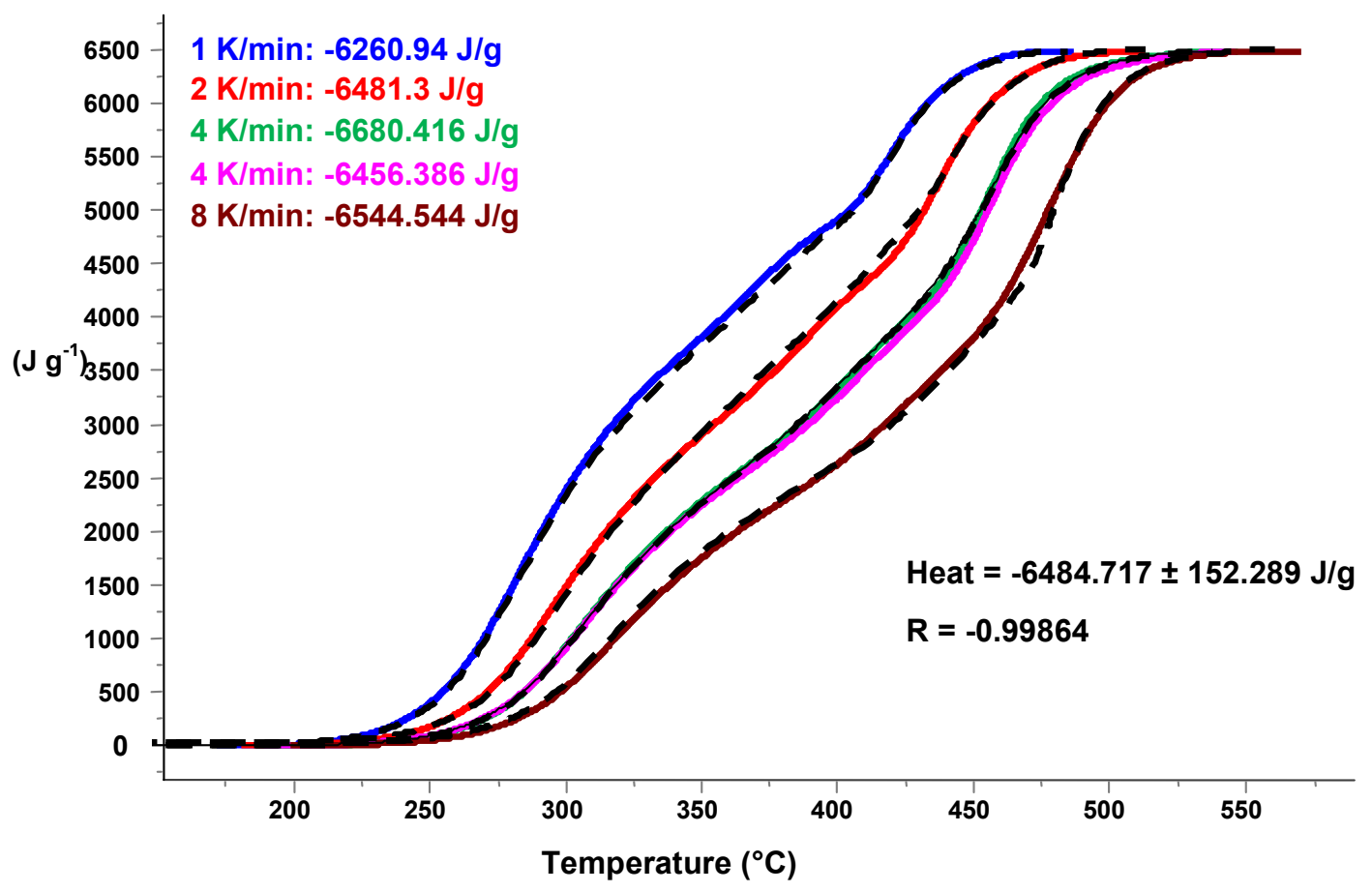

Figure 8: Reaction progress with heat released $\left(\mathrm{J} \mathrm{g}^{-1}\right)$ versus the temperature for the DMP where the coloured and dashed black curves show the practical and theoretical calculations, respectively. 


\subsubsection{Kinetic models discussion:}

Miscanthus is a lignocellulosic biomass with a composition of cellulose, hemicellulose, and lignin. The first two components decompose in the range of $200-380{ }^{\circ} \mathrm{C}$, while the third component decomposes over a wide range of temperature $\left(180-600{ }^{\circ} \mathrm{C}\right)$ and is considered as the rate determining step during the combustion/pyrolysis of lignocellulosic biomass ${ }^{61}$. Therefore, the model fitting method is not feasible for detecting the kinetic parameters for DMP as the reaction mechanism is complicated and there are overlapping reactions during the combustion/pyrolysis process. Usually, the TGA analysis shows the thermal decomposition of biomass in three stages of weight loss namely, dehydration, devolatilisation (active pyrolysis) and char oxidation (passive pyrolysis) ${ }^{62}$. The apparent activation energy $\left(\mathrm{Ea}=22.3 \mathrm{~kJ} \mathrm{~mol}^{-1}\right)$ 
calculated with the ASTM-E698 method based on Equation 6 is shown in Figure 10. One value of Ea is insufficient to describe the thermal decomposition of DMP as the reaction is complex and hence the ASTM-E698 method is inaccurate in this case.

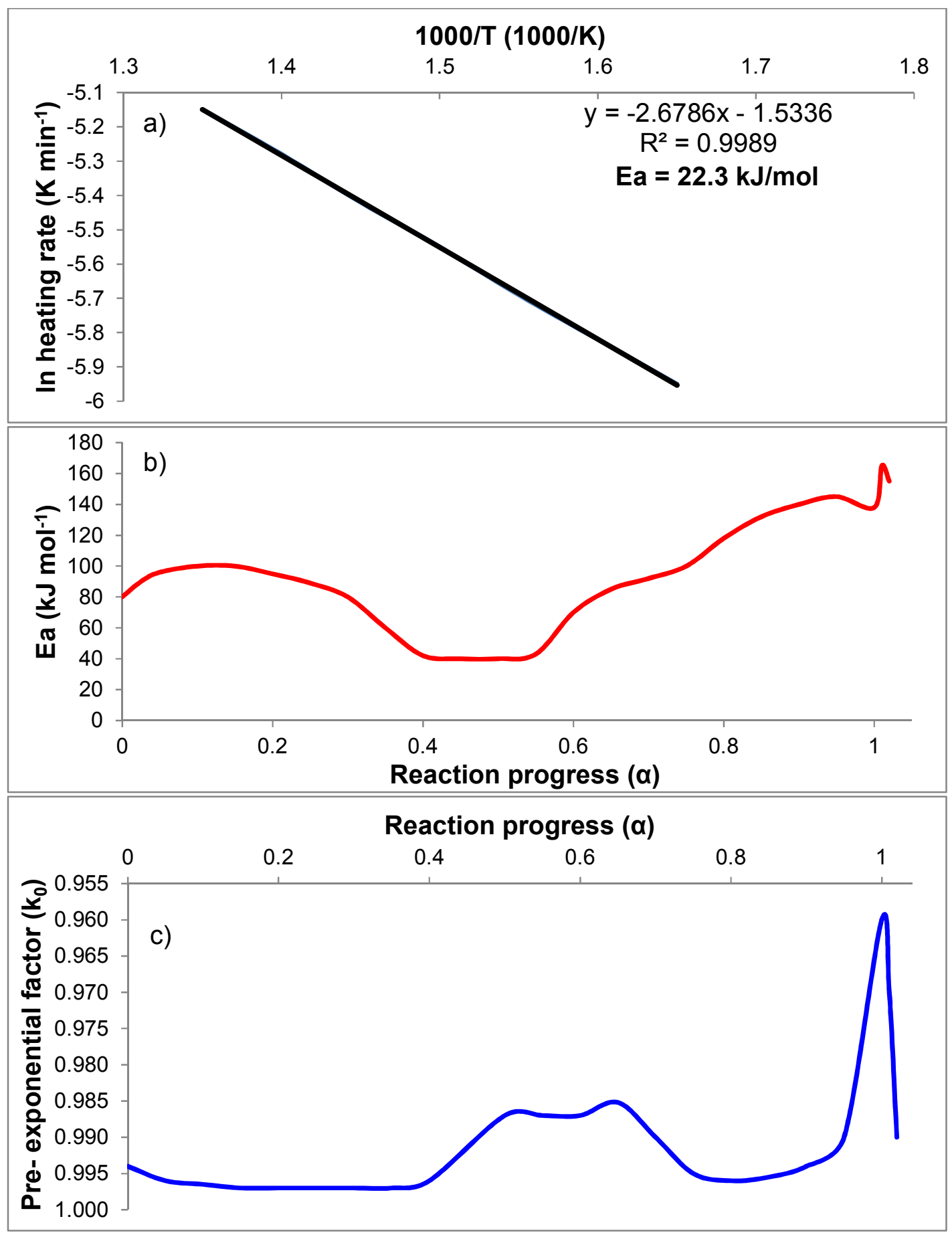

Figure 10: Kinetic parameters calculated by different methods (a) Ea using the ASTM-E698 method and (b) Ea, (c) pre-exponential factor using the Flynn-Wall and Ozawa (FWO) method. 
The iso-conversional method (model-free) is a convenient method for detecting the kinetic parameters as it provides a variation trend of the Ea and Ko as a function of the reaction progress $(\alpha)^{51}$.

The Flynn-Wall and Ozawa method (FWO) is more accurate as it shows that the kinetic parameters including the Ea change during the reaction progress. The Ea and the preexponential factor $\left(\mathrm{k}_{0}\right)$ calculated with the FWO method are shown in Figure $10(\mathrm{~b}, \mathrm{c})$. The variation in the Ea during the reaction progress was in the range of $40-150 \mathrm{~kJ} \mathrm{~mol}^{-1}$. Then, the differential iso-conversional method was used to calculate the kinetic parameters using the AKTS software as in Figures 11 and 12. Figure 11 shows the natural logarithm of the reaction rate in $\left(\mathrm{s}^{-1}\right)$ versus the inverse temperature, while the detected Ea along with the $\mathrm{K}_{0}$ were shown in Figure 12 (top curve). From the differential iso-conversional method, the Ea is initially high (at $\sim 110 \mathrm{~kJ} \mathrm{~mol}^{-1}$ ) at the start of the reaction where reaction progress was still zero $(\alpha=0)$ with $\ln (\mathrm{A}(\alpha) \mathrm{f}(\alpha))$ is about $15 \mathrm{~s}^{-1}$. It is well known that the carbohydrate polymer (cellulose and hemicellulose) are tightly bound to the lignin, so it is not surprising that the Ea value was high at the start of the reaction as energy is needed to overcome these strong bonds in order for the combustion reaction to proceed. Then Ea value declined to $40 \mathrm{~kJ} \mathrm{~mol}^{-1}$ as the $\alpha$ reached 0.4 . Due to the lignocellulosic biomass composition, the mechanism of Miscanthus combustion is extremely complex. Cellulose and hemicellulose components decompose in the range of 200$380{ }^{\circ} \mathrm{C}$, while the lignin decomposes over a wide range of temperature $\left(180-600{ }^{\circ} \mathrm{C}\right)$ and each of these components can combust via parallel exothermic reactions (as shown in the ninesteps mechanism). As such, the activation energy should decrease ${ }^{61}$. Finally, as $\alpha=0.77$, there was a further increase in the $\mathrm{Ea}\left(>160 \mathrm{~kJ} \mathrm{~mol}^{-1}\right)$ which is generally attributed to complex and/or autocatalytic reactions with several steps with the decomposition of lignin and formation of $\operatorname{ash}^{57}$. 
Herein, the calculated Ea using the differential iso-conversional method was in the range of 40$165 \mathrm{~kJ} \mathrm{~mol}^{-1}$ and in agreement with other studies. Jayaraman et al. ${ }^{18}$ reported activation energy values for poplar wood, hazelnut shell and wheat bran in the range of $66.80-68.56,83.73-$ 93.25 and 162.17-167.4 $\mathrm{kJ} \mathrm{mol}^{-1}$, respectively. Kok and Ozgur reported a variation in the activation energy values between 83.8 and $191.7 \mathrm{~kJ} \mathrm{~mol}^{-1}$ for hazelnut shell using OFW and KAS methods, respectively ${ }^{21}$. Munir et al. ${ }^{52}$ reported the activation energy for different lignocellulosic biomass such as cotton stalk, shea meal and sugarcane while the activation energy values ranged from 108 to $116 \mathrm{~kJ} \mathrm{~mol}^{-1}$. The activation energy was previously reported by Cortes and Bridgwater ${ }^{44}$ which was in the range of $129-156 \mathrm{~kJ} \mathrm{~mol}^{-1}$.

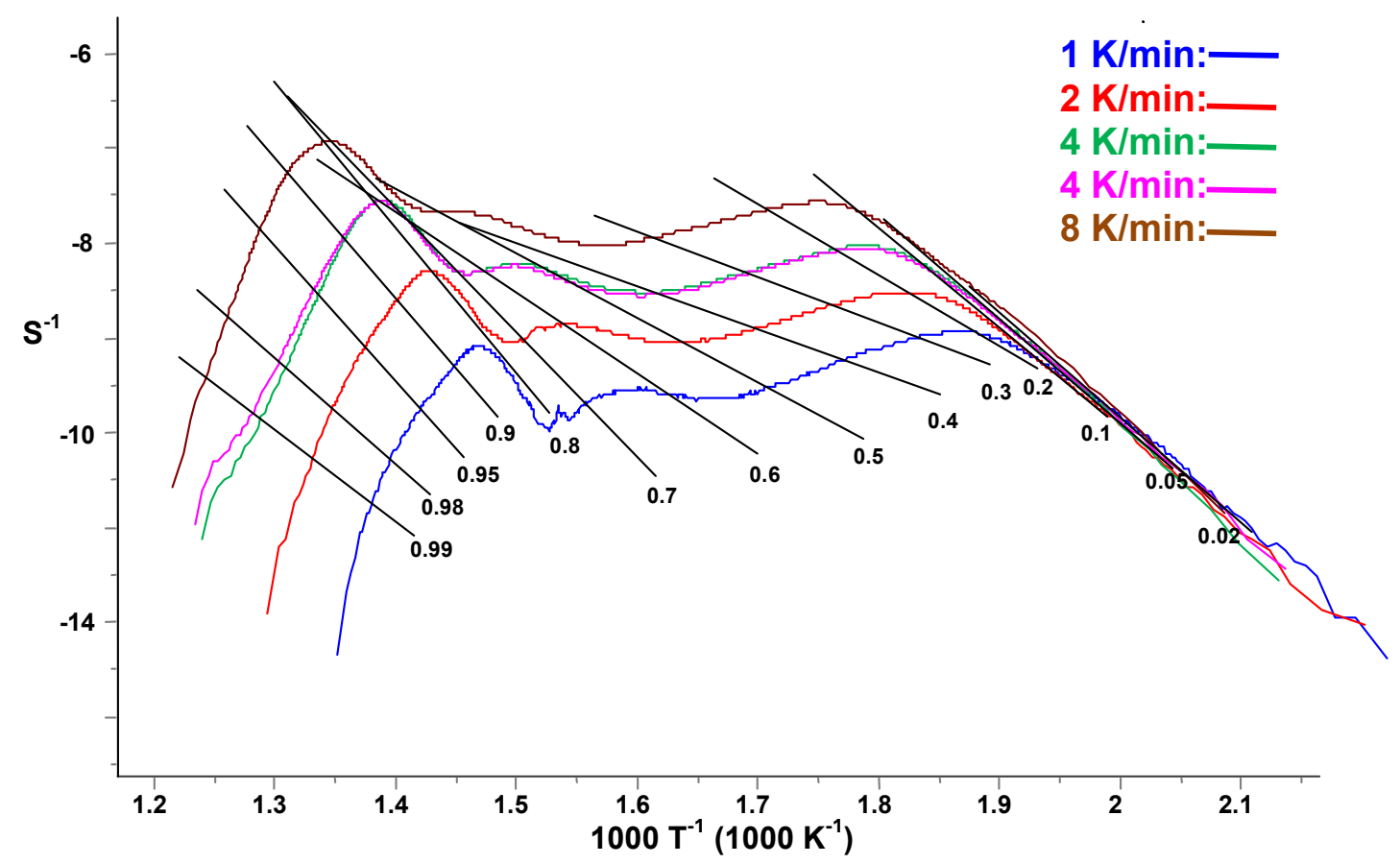

Figure 11: Natural logarithm of the reaction rate in $\left(\mathrm{s}^{-1}\right)$ versus the inverse temperature using the differential iso-conversional method. 

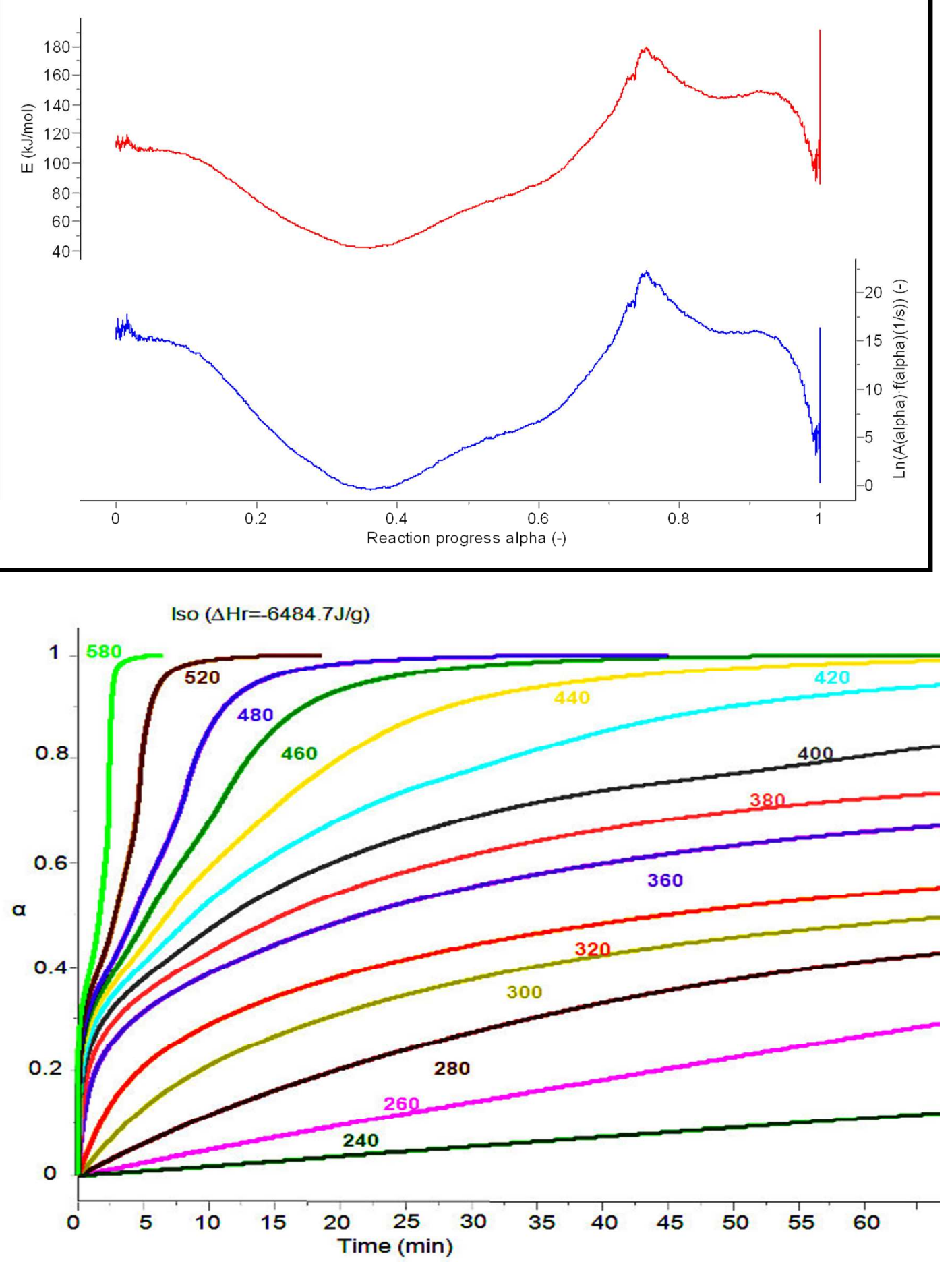

Figure 12: Kinetic parameters calculated with the differential iso-conversional (top) along with the isothermal prediction of DMP combustion using AKTS software (bottom). 


\subsubsection{Kinetic models prediction:}

The kinetic prediction of DMP isothermal combustion using the AKTS software is shown in Figure 12. Clearly, a temperature higher than $240{ }^{\circ} \mathrm{C}$ is needed to start the decomposition the DMP sample. There was only $10 \%(\alpha=0.1)$ of the sample decomposed after $1 \mathrm{hr}$ at $260{ }^{\circ} \mathrm{C}$. By increasing the temperature to $400{ }^{\circ} \mathrm{C}, 80 \%(\alpha=0.8)$ of the DMP decomposed over the same period of time under isothermal conditions. While at $480{ }^{\circ} \mathrm{C}$, the DMP sample decomposed completely $(\alpha=1)$ after 17.5 minutes.

\subsubsection{Thermal analysis of Miscanthus biochar:}

The thermal pyrolysis of miscanthus biochar-650 (pyrolyzed at $650^{\circ} \mathrm{C}$ under $\mathrm{N}_{2}$ atmosphere with the TGA and DTG analyses is shown in Figure $13(\mathrm{a}, \mathrm{b})$. Typically, the active pyrolysis zone (the highest rate of weight loss at rapid thermal decomposition) for any lignocellulosic biomass takes place in the temperature range of $360-490{ }^{\circ} \mathrm{C}{ }^{63,} 64$. However, in the case of DMP, the active zone was at $301{ }^{\circ} \mathrm{C}$ with a heating rate of $2.5{ }^{\circ} \mathrm{C} \mathrm{min}{ }^{-1}$ and shifted toward higher temperature $\left(333{ }^{\circ} \mathrm{C}\right.$ ) with a heating rate of $30{ }^{\circ} \mathrm{C} \min ^{-1}$ (not shown), due to the high content of volatile organics in DMP. During the pyrolysis process, some of these volatile organic compounds are released and consequently, the active zone of the biochar-650 started at $367{ }^{\circ} \mathrm{C}$ at a heating rate of $2.5^{\circ} \mathrm{C} \min ^{-1}$ with overlapping of a second sharp peak at $405{ }^{\circ} \mathrm{C}$ as seen in Figure 13. As expected, the active zone was shifted to a higher temperature and it became broader in the temperature range of $350-600{ }^{\circ} \mathrm{C}$. The biochar yield was calculated according to Equation 10.

$$
\text { (\%)Yield }=\frac{X}{Y} \times 100
$$

Equation 10

Where: $\mathrm{X}$ and $\mathrm{Y}$ are the weights of the produced biochar-650 and the DMP used for the pyrolysis, respectively, where the yield was $40 \%$ and this is in agreement with the previous work done by Maiti et al. ${ }^{63}$. The DSC curve of miscanthus biochar-650 combustion is shown in 
Figure $13(\mathrm{c})$. There are two clear decomposition peaks around 350 and $400{ }^{\circ} \mathrm{C}$ at slow heating rates (i.e. 1,2 , and $4{ }^{\circ} \mathrm{C} \min ^{-1}$ ), while at $8{ }^{\circ} \mathrm{C} \min ^{-1}$ these two peaks are merged in one broad peak. The miscanthus biochar-650 was easier to combust compared with the DMP as the ignition temperature declined from $295{ }^{\circ} \mathrm{C}$ for DMP to $242{ }^{\circ} \mathrm{C}$ with a heating rate of $2{ }^{\circ} \mathrm{C} \mathrm{min}{ }^{-1}$ as seen in Figure S2. The burnout temperature in contrast increased by about $30{ }^{\circ} \mathrm{C}$ for the miscanthus biochar-650. The heat released during the combustion of DMP and miscanthus biochar-650 are comparable at approximately $290 \mathrm{~W} \mathrm{~g}^{-1}$. The $\mathrm{pH}$ of the DMP and the miscanthus biochar- 650 solutions were investigated in order to differentiate between the nature of these two species by soaking and boiling them in deionized water and measuring the $\mathrm{pH}$ value prior and after the test using an electronic pH meter (Jenway 3510) as seen in Figure S3. The DMP solution is acidic with a $\mathrm{pH}$ of 6.44 due to the leaching of the acidic organic groups of cellulose, hemicellulose and lignin. On the other hand, miscanthus biochar-650 solution is basic with $\mathrm{pH}$ of 9.79 due to the leaching of the alkali metal salts in the biochar ${ }^{65}$. These results are in line with the work done by Maiti et al. ${ }^{63}$. 


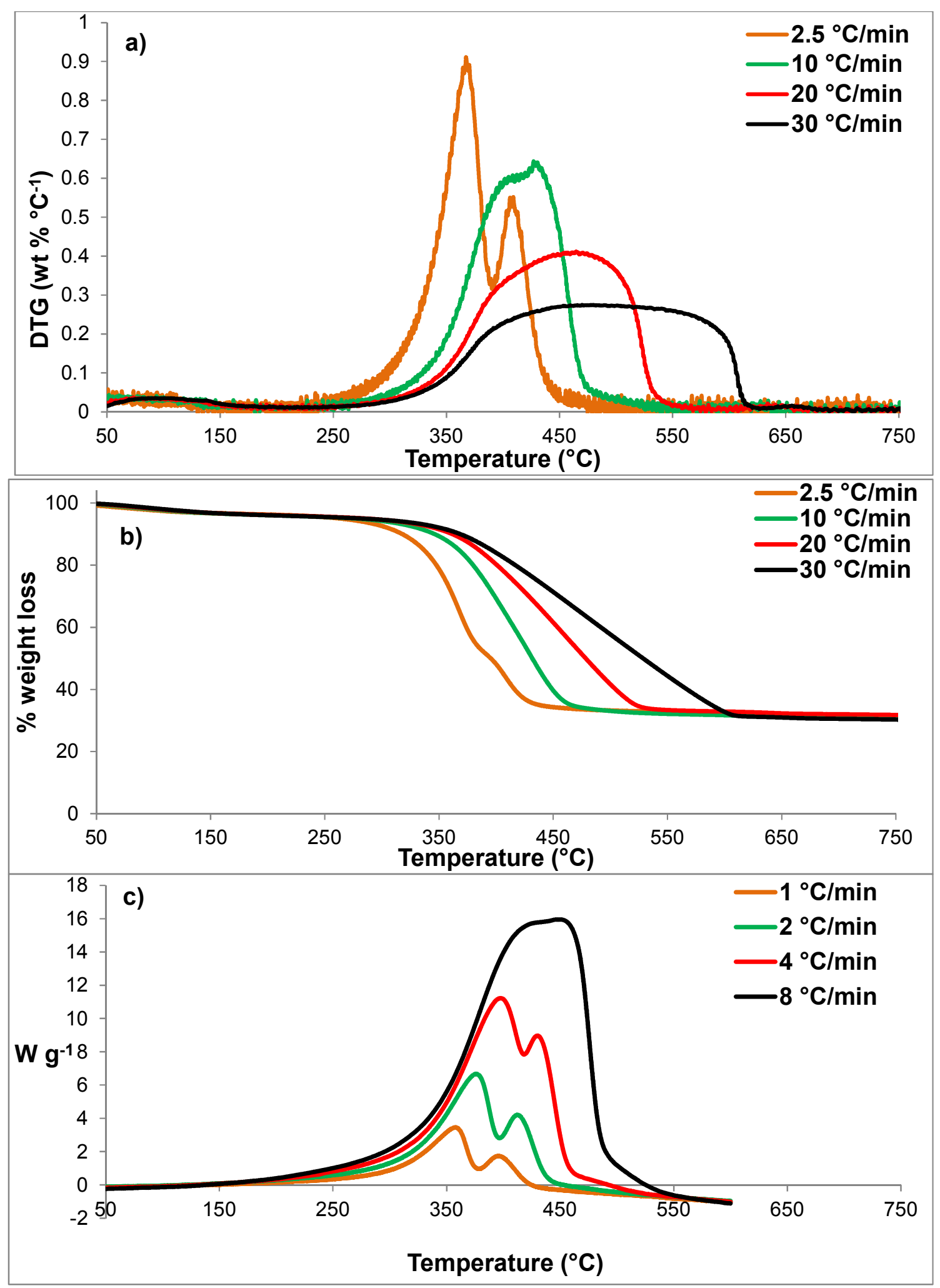

Figure 13: TGA (a) and DTG (b) and DSC (c) curves of miscanthus Biochar produced at 650 ${ }^{\circ} \mathrm{C}$ with different heating rates under $\mathrm{N}_{2}$ atmosphere for TGA, DTG and air for DSC. 


\section{Enormous potential applications of miscanthus species:}

\subsection{Miscanthus ash in fertilizers composition:}

The XRD pattern of miscanthus ash in Figure S4 shows the presence of various inorganic potassium salts such as potassium hydrogen disilicate $\left(\mathrm{KHSi}_{2} \mathrm{O}_{5}\right)$ and potassium chloride $(\mathrm{KCl})$ which are the most dominant constituents in the miscanthus ash, along with $\mathrm{K}_{4} \mathrm{H}_{2}\left(\mathrm{CO}_{3}\right)_{3.1} 1 \frac{1}{2}$ $\mathrm{H}_{2} \mathrm{O}$ and $\mathrm{KHCO}_{3}$. These inorganic salts represent 23.8 wt.\% of the miscanthus ash as seen in Figure S5. These results were also supported by the SEM analysis using the back-scattered electrons detector (BSED) ${ }^{66}$ and in agreement with the literature for the woody ash ${ }^{67}$. Lighter spots are apparent in the miscanthus ash SEM which also indicates the presence of these inorganic salts, as seen in Figure 14. The inference being that miscanthus ash can be used as a potential source of potassium in the fertilizer industry.

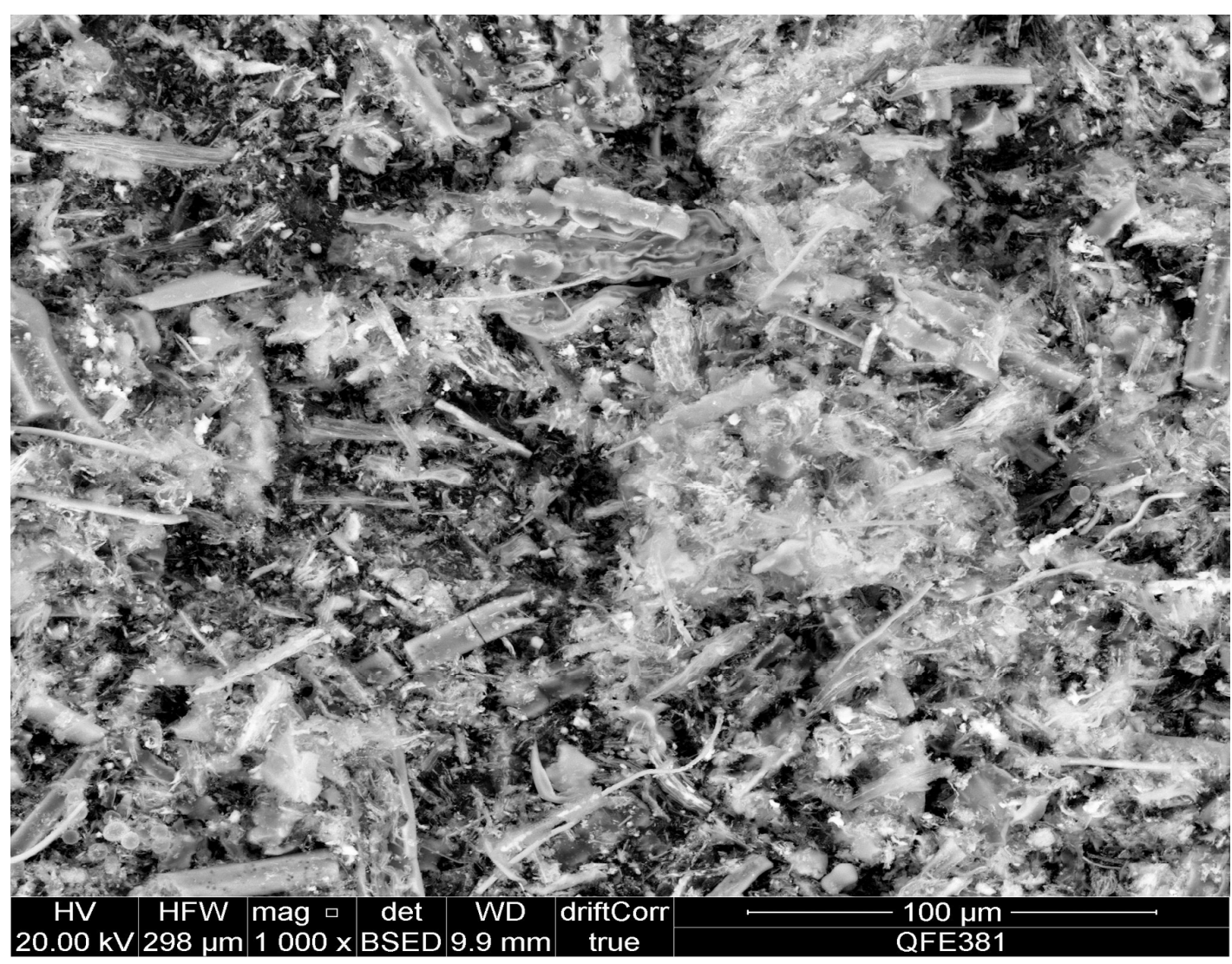

Figure 14: The SEM image of the miscanthus ash using the backscattered electron detector (BSED) at a magnification of 1000x. 


\subsection{Application of dry miscanthus plant and its biochar in heavy metal removal:}

We selected Cd for the heavy metal removal test as like other heavy metals it is extremely dangerous even at very low concentrations ${ }^{68}$. It is obvious that both biochar-650 and biochar950 are more active than DMP in Cd removal most likely due to the formation of activated carbon in the biochar. High percentage removals capacities of 93, 99.4 and $99.9 \%$ for DMP, biochar-650 and biochar-950, respectively over 7 days were detected as seen in Figure 15. Most of the \% removal was achieved in the first hours of the test making the DMP or its biochar derivatives potentially ideal in the continuous treatment of wastewater or other polluted waste streams. There is the requirement for future research to examine what miscanthus pre-treatments might improve its efficiency in removing heavy metals from aqueous solutions followed by additional downstream recovery.

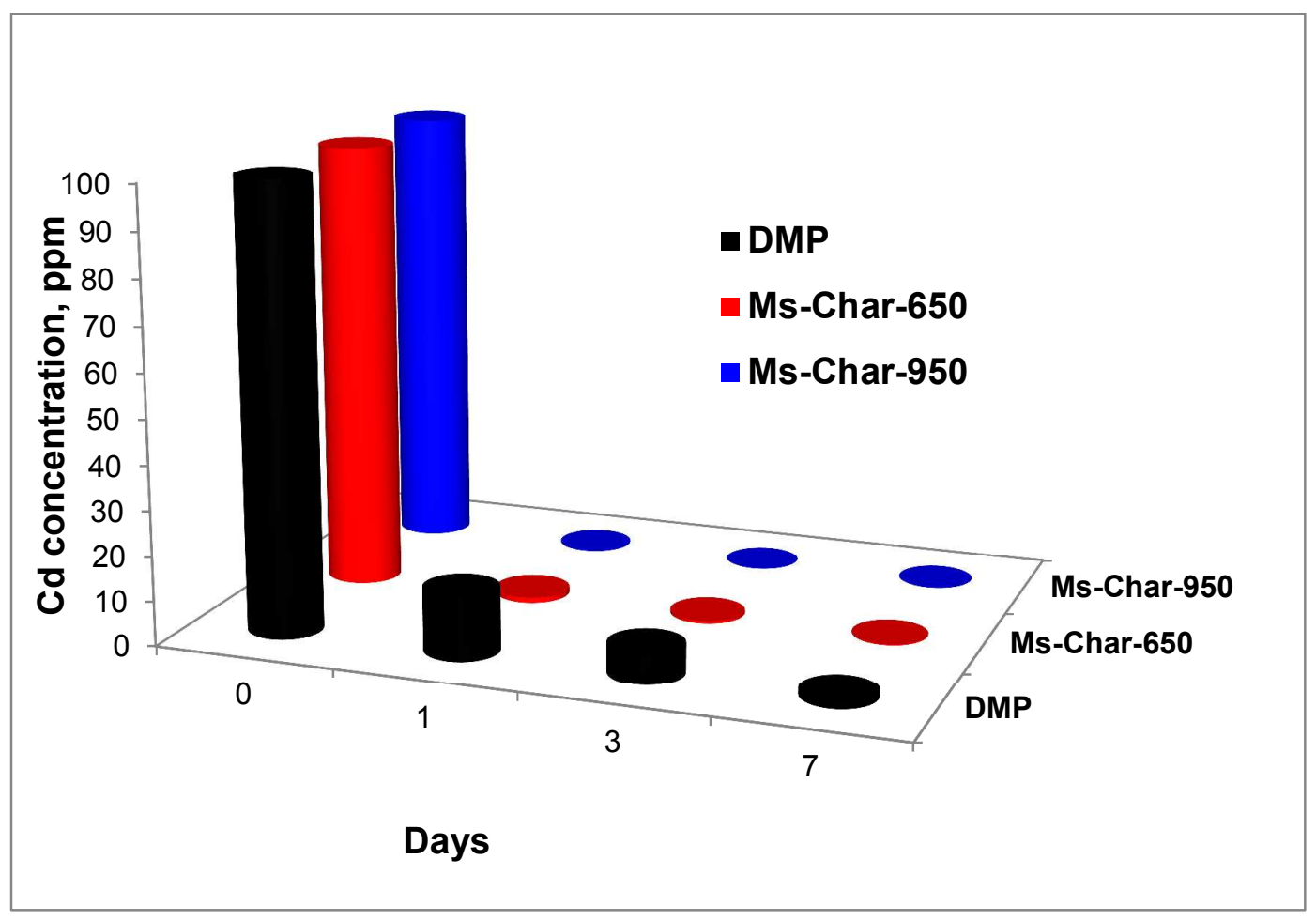

Figure 15: Miscanthus absorption cadmium with L/S ratio of 20 over a period of time up to 7 days. 


\section{Conclusions}

Herein, the thermal and kinetic analysis of dry miscanthus plant and its char were investigated. The activation energy was calculated using the ASTM-E698 method and was determined to be $22.3 \mathrm{~kJ} \mathrm{~mol}^{-1}$. One value of Ea, however, is insufficient to describe the thermal decomposition of lignocellulosic biomass (miscanthus) as the reaction is complex and hence the ASTM-E698 method was inaccurate. The Ea and the pre-exponential factor $\left(\mathrm{k}_{0}\right)$ were therefore calculated with the FWO method which showed a variation in the Ea during the reaction progress in the range of $40-150 \mathrm{~kJ} \mathrm{~mol}^{-1}$. While the differential iso-conversional method showed activation energy values in the range of $40-165 \mathrm{~kJ} \mathrm{~mol}^{-1}$. Therefore, the FWO and differential isoconversional methods were more accurate than the ASTM-E698 method for calculating the activation energy and the kinetic parameters during the combustion/pyrolysis process of the DMP. The kinetic prediction of DMP isothermal combustion showed that a temperature higher than $240{ }^{\circ} \mathrm{C}$ is needed to start the decomposition the DMP sample. The miscanthus biochar- 650 was found to be promising in terms of its enhanced combustibility. There is the potential for a new application of miscanthus in wastewater treatment; in particular the fast removal of heavy metals such as cadmium. Moreover, miscanthus ash could potentially be used as a source of potassium in the fertilizer industry. 
Supporting Information: Images of miscanthus, DSC curves, The $\mathrm{pH}$ of the DPM and miscanthus biochar-650, XRD pattern, EDX data, Elemental and proximate analysis.

Acknowledgment: The authors would like to acknowledge the support given by the School of Chemistry and Chemical Engineering, Queen's University Belfast.

Competing financial interests: The authors declare no competing financial interests.

\section{AUTHOR INFORMATION}

\section{Corresponding Author}

* Corresponding Author: Dr Ahmed Osman Email: aosmanahmed01@qub.ac.uk

ORCID: Ahmed Osman: 0000-0003-2788-7839

Address: School of Chemistry and Chemical Engineering, Queen's University, David Keir Building, Stranmillis Road, Belfast BT9 5AG, Northern Ireland, United Kingdom. Fax: +44 289097 4687, Tel.: +442890974412. 


\section{References}

1. Absi Halabi, M.; Al-Qattan, A.; Al-Otaibi, A., Application of solar energy in the oil industry-Current status and future prospects. Renewable Sustainable Energy Rev. 2015, 43, 296-314.

2. Al-Hamamre, Z.; Saidan, M.; Hararah, M.; Rawajfeh, K.; Alkhasawneh, H. E.; Al-Shannag, M., Wastes and biomass materials as sustainable-renewable energy resources for Jordan. Renewable Sustainable Energy Rev. 2017, 67, 295-314.

3. Apergis, N.; Payne, J. E., Renewable energy, output, $\mathrm{CO}_{2}$ emissions, and fossil fuel prices in Central America: Evidence from a nonlinear panel smooth transition vector error correction model. Energy Econ. 2014, 42, 226-232.

4. Fernández, R. G.; García, C. P.; Lavín, A. G.; Bueno de las Heras, J. L., Study of main combustion characteristics for biomass fuels used in boilers. Fuel Process. Technol. 2012, 103, $16-26$.

5. Sezer, İ., Thermodynamic, performance and emission investigation of a diesel engine running on dimethyl ether and diethyl ether. Int. J. Therm. Sci. 2011, 50, (8), 1594-1603.

6. Pelet, X.; Favrat, D.; Leyland, G., Multiobjective optimisation of integrated energy systems for remote communities considering economics and $\mathrm{CO}_{2}$ emissions. Int. J. Therm. Sci. 2005, 44, (12), 1180-1189.

7. Nie, J.; Chen, Y.; Cohen, S.; Carter, B. D.; Boehm, R. F., Numerical and experimental study of three-dimensional fluid flow in the bipolar plate of a PEM electrolysis cell. Int. J. Therm. Sci. 2009, 48, (10), 1914-1922.

8. Koçar, G.; Civaş, N., An overview of biofuels from energy crops: Current status and future prospects. Renewable Sustainable Energy Rev. 2013, 28, 900-916.

9. Guo, M.; Bi, J.-C., Characteristics and application of co-pyrolysis of coal/biomass blends with solid heat carrier. Fuel Process. Technol. 2015, 138, 743-749.

10. Franco, A.; Giannini, N., Perspectives for the use of biomass as fuel in combined cycle power plants. Int. J. Therm. Sci. 2005, 44, (2), 163-177.

11. Mahmoudi, A. H.; Hoffmann, F.; Peters, B., Application of XDEM as a novel approach to predict drying of a packed bed. Int. J. Therm. Sci. 2014, 75, 65-75.

12. Proskurina, S.; Sikkema, R.; Heinimö, J.; Vakkilainen, E., Five years left - How are the EU member states contributing to the $20 \%$ target for EU's renewable energy consumption; the role of woody biomass. Biomass Bioenergy 2016, 95, 64-77.

13. Morandi, F.; Perrin, A.; Østergård, H., Miscanthus as energy crop: Environmental assessment of a miscanthus biomass production case study in France. J. Cleaner Prod. 2016, 137, 313-321.

14. Bens, O.; Hüttl, R. F., Energetic utilisation of wood as biochemical energy carrier - A contribution to the utilisation of waste energy and landuse. Int. J. Therm. Sci. 2001, 40, (4), 344-351.

15. Kołodziej, B.; Antonkiewicz, J.; Sugier, D., Miscanthus $\times$ giganteus as a biomass feedstock grown on municipal sewage sludge. Ind. Crops Prod. 2016, 81, 72-82.

16. Sommersacher, P.; Brunner, T.; Obernberger, I.; Kienzl, N.; Kanzian, W., Combustion related characterisation of Miscanthus peat blends applying novel fuel characterisation tools. Fuel 2015, 158, 253-262.

17. Elmay, Y.; Brech, Y. L.; Delmotte, L.; Dufour, A.; Brosse, N.; Gadiou, R., Characterization of Miscanthus pyrolysis by DRIFTs, UV Raman spectroscopy and mass spectrometry. J. Anal. Appl. Pyrolysis 2015, 113, 402-411. 
18. Jayaraman, K.; Kok, M. V.; Gokalp, I., Combustion properties and kinetics of different biomass samples using TG-MS technique. J. Therm. Anal. Calorim. 2017, 127, (2), 13611370 .

19. Jayaraman, K.; Kok, M. V.; Gokalp, I., Thermogravimetric and mass spectrometric (TGMS) analysis and kinetics of coal-biomass blends. Renewable Energy 2017, 101, (Supplement C), 293-300.

20. Özgür, E.; Miller, S. F.; Miller, B. G.; Kök, M. V., THERMAL ANALYSIS OF COFIRING OF OIL SHALE AND BIOMASS FUELS. Oil Shale 2012, 29, (2), 190-201.

21. Kok, M. V.; Ozgur, E., Characterization of lignocellulose biomass and model compounds by thermogravimetry. Energy Sources, Part A 2017, 39, (2), 134-139.

22. Brosse, N.; Dufour, A.; Meng, X.; Sun, Q.; Ragauskas, A., Miscanthus: a fast-growing crop for biofuels and chemicals production. Biofuels, Bioprod. Biorefin. 2012, 6, (5), 580-598.

23. Lewandowski, I.; Clifton-Brown, J. C.; Scurlock, J. M. O.; Huisman, W., Miscanthus: European experience with a novel energy crop. Biomass Bioenergy 2000, 19, (4), 209-227.

24. Chung, J.-H.; Kim, D.-S., Miscanthus as a potential bioenergy crop in East Asia. J. Crop Sci. Biotechnol. 2012, 15, (2), 65-77.

25. Xue, S.; Lewandowski, I.; Wang, X.; Yi, Z., Assessment of the production potentials of Miscanthus on marginal land in China. Renewable Sustainable Energy Rev. 2016, 54, 932943.

26. McKendry, P., Energy production from biomass (part 2): conversion technologies. Bioresour. Technol. 2002, 83, (1), 47-54.

27. Lappa, E.; Christensen, P. S.; Klemmer, M.; Becker, J.; Iversen, B. B., Hydrothermal liquefaction of Miscanthus $\times$ Giganteus: Preparation of the ideal feedstock. Biomass Bioenergy 2016, 87, 17-25.

28. Yu, C.; Thy, P.; Wang, L.; Anderson, S. N.; VanderGheynst, J. S.; Upadhyaya, S. K.; Jenkins, B. M., Influence of leaching pretreatment on fuel properties of biomass. Fuel Process. Technol. 2014, 128, 43-53.

29. Jayaraman, K.; Gökalp, I., Pyrolysis, combustion and gasification characteristics of miscanthus and sewage sludge. Energy Convers. Manage. 2015, 89, 83-91.

30. Nguyen, T. L. T.; Hermansen, J. E., Life cycle environmental performance of miscanthus gasification versus other technologies for electricity production. Sustainable Energy Technol. Assess. 2015, 9, 81-94.

31. Cai, J. M.; Bi, L. S., Kinetic analysis of wheat straw pyrolysis using isoconversional methods. J. Therm. Anal. Calorim. 2009, 98, (1), 325.

32. Houben, D.; Sonnet, P.; Cornelis, J.-T., Biochar from Miscanthus: a potential silicon fertilizer. Plant Soil 2014, 374, (1), 871-882.

33. Peng, S.-W.; Besant, R. W.; Strathdee, G., Measurement of the enthalpy change during potash-moisture interactions. Int. J. Therm. Sci. 2001, 40, (6), 586-594.

34. Kim, W.-K.; Shim, T.; Kim, Y.-S.; Hyun, S.; Ryu, C.; Park, Y.-K.; Jung, J., Characterization of cadmium removal from aqueous solution by biochar produced from a giant Miscanthus at different pyrolytic temperatures. Bioresour. Technol. 2013, 138, 266-270.

35. Tan, X.; Liu, Y.; Zeng, G.; Wang, X.; Hu, X.; Gu, Y.; Yang, Z., Application of biochar for the removal of pollutants from aqueous solutions. Chemosphere 2015, 125, 70-85.

36. Nowak, B.; Aschenbrenner, P.; Winter, F., Heavy metal removal from sewage sludge ash and municipal solid waste fly ash - A comparison. Fuel Process. Technol. 2013, 105, 195201.

37. Vyazovkin, S.; Chrissafis, K.; Di Lorenzo, M. L.; Koga, N.; Pijolat, M.; Roduit, B.; Sbirrazzuoli, N.; Suñol, J. J., ICTAC Kinetics Committee recommendations for collecting 
experimental thermal analysis data for kinetic computations. Thermochim. Acta 2014, 590, (Supplement C), 1-23.

38. Wei, L.; Geng, P., A review on natural gas/diesel dual fuel combustion, emissions and performance. Fuel Process. Technol. 2016, 142, 264-278.

39. Institute BS. Solid biofuels. Determination of particle size distribution. Part 1: Oscillating screen method using sieve apertures of 1mm and above. BS EN15149-1; 2010.

40. Periyat, P.; Laffir, F.; Tofail, S. A. M.; Magner, E., A facile aqueous sol-gel method for high surface area nanocrystalline $\mathrm{CeO}_{2}$. RSC Adv. 2011, 1, (9), 1794-1798.

41. Siedlecki, M.; de Jong, W., Biomass gasification as the first hot step in clean syngas production process - gas quality optimization and primary tar reduction measures in a $100 \mathrm{~kW}$ thermal input steam-oxygen blown CFB gasifier. Biomass Bioenergy 2011, 35, Supplement 1, S40-S62.

42. ASTM, Standard Test Method for Compositional Analysis by Thermogravimetry, http://dx.doi.org/10.1520/E1131-03. 2003.

43. ASTM, Standard Test Method for Ash in Biomass, http://www.astm.org/DATABASE.CART/HISTORICAL/E1755-01R07.htm. 2001.

44. Cortes, A. M.; Bridgwater, A. V., Kinetic study of the pyrolysis of miscanthus and its acid hydrolysis residue by thermogravimetric analysis. Fuel Process. Technol. 2015, 138, 184-193.

45. Serrano, L.; Egües, I.; Alriols, M. G.; Llano-Ponte, R.; Labidi, J., Miscanthus sinensis fractionation by different reagents. Chem. Eng. J. 2010, 156, (1), 49-55.

46. Poletto, M.; Zattera, A. J., Materials produced from plant biomass: part III: degradation kinetics and hydrogen bonding in lignin. Mater. Res. 2013, 16, 1065-1070.

47. Osman, A. I.; Abu-Dahrieh, J. K.; Laffir, F.; Curtin, T.; Thompson, J. M.; Rooney, D. W., A bimetallic catalyst on a dual component support for low temperature total methane oxidation. Appl. Catal., B 2016, 187, 408-418.

48. Yang, H.; Yan, R.; Chen, H.; Lee, D. H.; Zheng, C., Characteristics of hemicellulose, cellulose and lignin pyrolysis. Fuel 2007, 86, (12-13), 1781-1788.

49. Kok, M. V.; Ozgur, E., Thermal analysis and kinetics of biomass samples. Fuel Process. Technol. 2013, 106, 739-743.

50. Le Brech, Y.; Ghislain, T.; Leclerc, S.; Bouroukba, M.; Delmotte, L.; Brosse, N.; Snape, C.; Chaimbault, P.; Dufour, A., Effect of Potassium on the Mechanisms of Biomass Pyrolysis Studied using Complementary Analytical Techniques. ChemSusChem 2016, 9, (8), 863-872.

51. Álvarez, A.; Pizarro, C.; García, R.; Bueno, J. L.; Lavín, A. G., Determination of kinetic parameters for biomass combustion. Bioresour. Technol. 2016, 216, 36-43.

52. Munir, S.; Daood, S. S.; Nimmo, W.; Cunliffe, A. M.; Gibbs, B. M., Thermal analysis and devolatilization kinetics of cotton stalk, sugar cane bagasse and shea meal under nitrogen and air atmospheres. Bioresour. Technol. 2009, 100, (3), 1413-1418.

53. Huang, X.; Rein, G., Thermochemical conversion of biomass in smouldering combustion across scales: The roles of heterogeneous kinetics, oxygen and transport phenomena. Bioresour. Technol. 2016, 207, 409-421.

54. Opfermann, J. R.; Kaisersberger, E.; Flammersheim, H. J., Model-free analysis of thermoanalytical data-advantages and limitations. Thermochim. Acta 2002, 391, (1-2), 119127.

55. Sun, Y.-H.; Zhang, T.-L.; Zhang, J.-G.; Yang, L.; Qiao, X.-J., Decomposition kinetics of manganese tris (carbohydrazide) perchlorate (MnCP) derived from the filament control voltage of the T-jump/FTIR spectroscopy. Int. J. Therm. Sci. 2006, 45, (8), 814-818.

56. Le Bideau, P.; Ploteau, J.-P.; Dutournié, P.; Glouannec, P., Experimental and modelling study of superficial elastomer vulcanization by short wave infrared radiation. Int. J. Therm. Sci. 2009, 48, (3), 573-582. 
57. Iliyas, A.; Hawboldt, K.; Khan, F., Thermal stability investigation of sulfide minerals in DSC. J. Hazard. Mater. 2010, 178, (1-3), 814-822.

58. Zou, P.; Tang, S.; Fu, Z.; Xiong, H., Isothermal and non-isothermal crystallization kinetics of modified rape straw flour/high-density polyethylene composites. Int. J. Therm. Sci. 2009, 48, (4), 837-846.

59. Véchot, L.; Bombard, I.; Laurent, P.; Lieto, J., Experimental and modelling study of the radiative curing of a polyester-based coating. Int. J. Therm. Sci. 2006, 45, (1), 86-93.

60. Kumar, A.; Wang, L.; Dzenis, Y. A.; Jones, D. D.; Hanna, M. A., Thermogravimetric characterization of corn stover as gasification and pyrolysis feedstock. Biomass Bioenergy 2008, 32, (5), 460-467.

61. Islam, M. A.; Auta, M.; Kabir, G.; Hameed, B. H., A thermogravimetric analysis of the combustion kinetics of karanja (Pongamia pinnata) fruit hulls char. Bioresour. Technol. 2016, 200, 335-341.

62. Benkoussas, B.; Consalvi, J. L.; Porterie, B.; Sardoy, N.; Loraud, J. C., Modelling thermal degradation of woody fuel particles. Int. J. Therm. Sci. 2007, 46, (4), 319-327.

63. Maiti, S.; Dey, S.; Purakayastha, S.; Ghosh, B., Physical and thermochemical characterization of rice husk char as a potential biomass energy source. Bioresour. Technol. 2006, 97, (16), 2065-2070.

64. Johansson, A.-C.; Wiinikka, H.; Sandström, L.; Marklund, M.; Öhrman, O. G. W.; Narvesjö, J., Characterization of pyrolysis products produced from different Nordic biomass types in a cyclone pilot plant. Fuel Process. Technol. 2016, 146, 9-19.

65. Capablo, J., Formation of alkali salt deposits in biomass combustion. Fuel Process. Technol. 2016, 153, 58-73.

66. Niemantsverdriet, J. W., Spectroscopy in catalysis : An Introduction. In 2nd ed. ed.; WileyVCH: Weinheim ;, 2000.

67. Maeda, N.; Katakura, T.; Fukasawa, T.; Huang, A.-N.; Kawano, T.; Fukui, K., Morphology of woody biomass combustion ash and enrichment of potassium components by particle size classification. Fuel Process. Technol. 2017, 156, 1-8.

68. Purkayastha, D.; Mishra, U.; Biswas, S., A comprehensive review on Cd(II) removal from aqueous solution. J. Water Process Eng. 2014, 2, 105-128. 


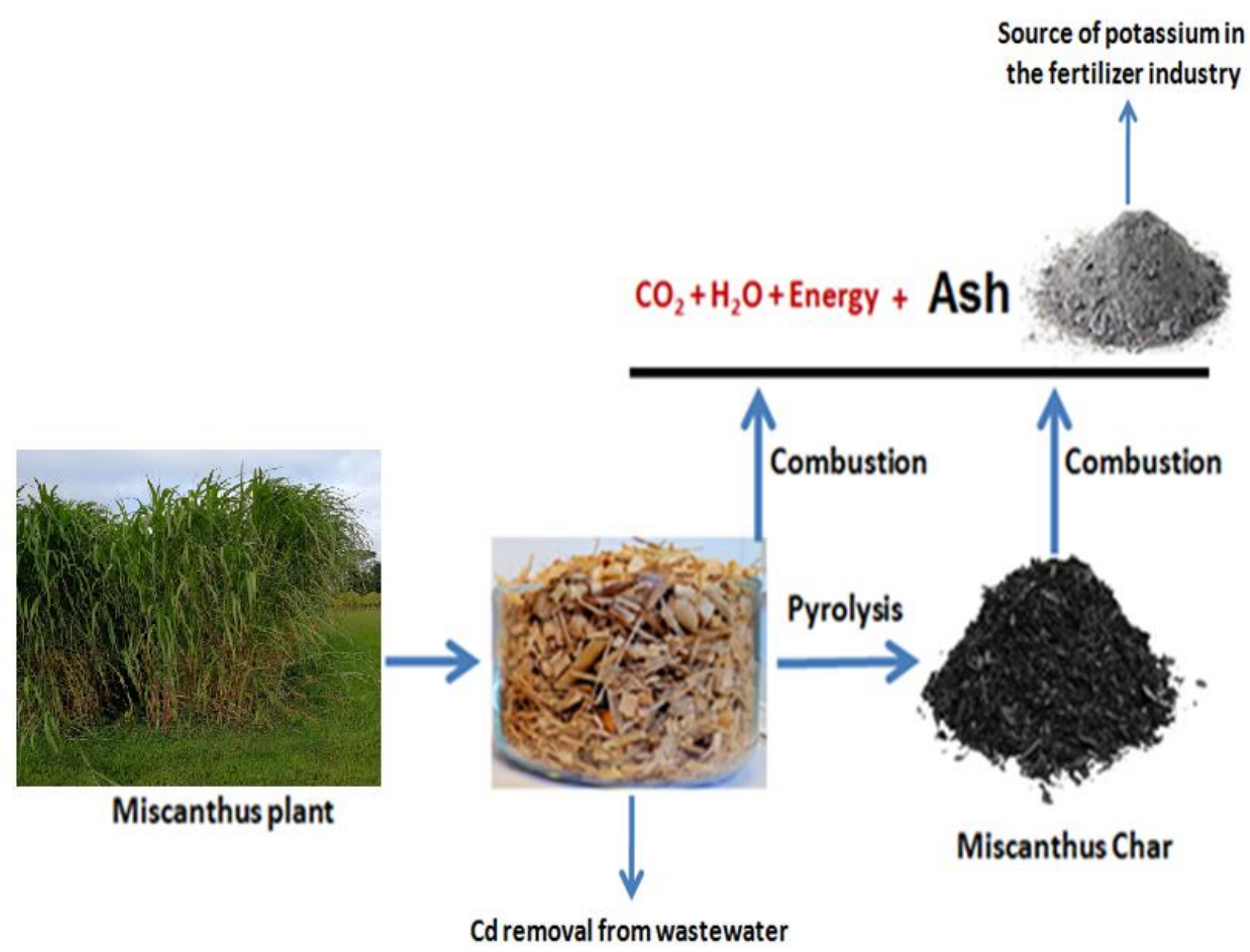

